\title{
CLOUDS, PRECIPITATION AND MARINE BOUNDARY LAYER STRUCTURE DURING THE MAGIC FIELD CAMPAIGN
}

\author{
Xiaoli Zhou ${ }^{1}$, Pavlos Kollias ${ }^{1}$, and Ernie R. Lewis ${ }^{2}$ \\ 1. Department of Atmospheric and Oceanic Sciences, McGill University, \\ Montreal, CA \\ 2. Biological, Environmental \& Climate Sciences Department, Brookhaven \\ National Laboratory, Upton, NY \\ Corresponding author: Xiaoli Zhou \\ Department of Atmospheric and Oceanic Sciences \\ Montreal H3A0B9 Quebec, Canada \\ email: xiaoli.zhou@mail.mcgill.ca \\ Accepted for publication in \\ the Journal of Climate
}

April 2014

\begin{abstract}
Biological, Environmental \& Climate Science Dept.
Brookhaven National Laboratory
\end{abstract}

\section{U.S. Department of Energy DOE Office of Science}

\footnotetext{
Notice: This manuscript has been authored by employees of Brookhaven Science Associates, LLC under Contract No. DE-SC0012704 with the U.S. Department of Energy. The publisher by accepting the manuscript for publication acknowledges that the United States Government retains a non-exclusive, paid-up, irrevocable, world-wide license to publish or reproduce the published form of this manuscript, or allow others to do so, for United States Government purposes.
} 


\section{DISCLAIMER}

This report was prepared as an account of work sponsored by an agency of the United States Government. Neither the United States Government nor any agency thereof, nor any of their employees, nor any of their contractors, subcontractors, or their employees, makes any warranty, express or implied, or assumes any legal liability or responsibility for the accuracy, completeness, or any third party's use or the results of such use of any information, apparatus, product, or process disclosed, or represents that its use would not infringe privately owned rights. Reference herein to any specific commercial product, process, or service by trade name, trademark, manufacturer, or otherwise, does not necessarily constitute or imply its endorsement, recommendation, or favoring by the United States Government or any agency thereof or its contractors or subcontractors. The views and opinions of authors expressed herein do not necessarily state or reflect those of the United States Government or any agency thereof. 
Abstract

27 The recent ship-based MAGIC field campaign with the marine-capable Second ARM

28 Mobile Facility (AMF2) deployed on the Horizon Lines cargo container M/V Spirit

29 provided nearly 200 days of intra-seasonal high-resolution observations of clouds,

30 precipitation and marine boundary layer (MBL) structure on multiple legs between Los

31 Angeles, California, and Honolulu, Hawaii. During the deployment, MBL clouds

32 exhibited a much higher frequency of occurrence than other cloud types and occurred

33 more often in the warm season than in the cold season. MBL clouds demonstrated a

34 propensity to produce precipitation, which often evaporated before reaching the ocean

35 surface. The formation of stratocumuli is strongly correlated to a shallow MBL with a

36 strong inversion and a weak transition, while cumuli formation is associated with a much

37 weaker inversion and stronger transition. The estimated inversion strength (EIS) is shown

38 to depend seasonally on the potential temperature at the $700 \mathrm{hPa}$. The location of the

39 commencement of systematic MBL decoupling (DE) always occurred eastward of the

40 locations of cloud breakup (CBs), and the systematic decoupling showed a strong

41 moisture stratification. The entrainment of the dry warm air above the inversion appears

42 to be the dominant factor triggering the systematic decoupling, while surface latent heat

43 flux, precipitation and solar radiation did not play major roles. MBL clouds broke up over

44 a short spatial region due to the changes in the synoptic conditions, implying that in real

45 atmospheric conditions, the MBL clouds do not have enough time to evolve as is in the 46 idealized models. 


\section{INTRODUCTION}

52 On average, near $30 \%$ of the global oceans are covered with low-level clouds (ISCCP

53 online data set: http://isccp.giss.nasa.gov/climanal7.html). These prevailing marine

54 boundary layer (MBL) clouds are a key component in the earth's radiation budget, from

55 which Stratocumulus (Sc) clouds exert a strong negative net radiative effect due to their

56 low height and high areal coverage, by strongly reflecting incoming solar radiation but

57 only weakly influencing the outgoing longwave radiation (Wood, 2006). Cumulus $(\mathrm{Cu})$

58 have a reduced effect on the radiation due to their low areal coverage (Wood, 2006;

59 Karlsson et al. 2010) but play a critical role in the vertical redistribution of moisture and

60 energy in the lower troposphere (Tiedke et al., 1988). Thus, it is important for global

61 climate models to accurately represent these cloud regimes.

62 The evolution, with increasing sea surface temperature (SST), from Sc regimes to $\mathrm{Cu}$

63 regimes in the trade wind regions and then eventually to congestus and deep convective

$64 \mathrm{Cu}$ over the warmer waters of the intertropical convergence zone are well documented

65 (e.g., Albrecht et al., 1995a,b; Kalsson et al., 2010). An inversion layer that is often

66 thought of as the top of the MBL typically caps the Sc. A regime with Cu-under-Sc

67 usually occurs during the progression between $\mathrm{Sc}$ and $\mathrm{Cu}$ and is associated with a weakly

68 stable layer below the inversion base that is characterized by a sharp decrease of moisture

69 with height (e.g. Krueger et al. 1995; Bretherton and Wyant, 1997; Jones et al. 2011). 
70 This stable layer, referred here as the transition layer, separates a region below of surface

71 flux-driven turbulence from a region above dominated by radiatively driven convection

72 (Bretherton and Wyant, 1997) and acts to isolate the upper MBL from the surface

73 moisture supply. When this vertical moisture stratification gets sufficiently strong,

74 systematic decoupling occurs, and remains decoupled with further increase in SST. This

75 systematic decoupling is a crucial first step in the Sc-to-Cu transition and is not affected

76 by the diurnal cycle of radiation (Wyant et al. 1997).

77 Due to the lack of fully understanding of the mechanisms responsible for the evolution of

78 MBL structure and cloud, global weather and climate prediction models still do not

79 accurately reproduce the evolution between these cloud regimes, and the locations of Sc

80 breakup and the rates of change of cloud coverage vary widely among different models,

81 which generally underestimate cloud amounts in the Sc region while overestimating them

82 in the $\mathrm{Cu}$ region (Teixeira et al., 2011).

83 One of the main factors hindering progress in representing these clouds in numerical 84 models has been the lack of observational data. Most of the observational data sets used 85 to evaluate the cloud-related processes are satellite-based. Satellite data have proven 86 valuable in determining the climatological links between MBL inversion base height 87 (MBLH) and cloud cover (e.g. Heck et al. 1990; Wang et al. 1993; Wood and Bretherton, 88 2004). However, satellite observations cannot provide information on detailed vertical 89 cloud and thermodynamic structure of the MBL especially during decoupling conditions

90 (Wood and Bretherton, 2004; Kalsson et al. 2010). The difficulty in accurately observing 91 low-level clouds with small-scale variability (Xu and Cheng, 2013) further restricts the 92 applicability of satellite data in the understanding of the transition between these cloud 
93 regimes.

94 In addition to satellite data, several field campaigns have been conducted to study MBL

95 clouds and the mechanisms responsible for the $\mathrm{Sc}-$ to- $\mathrm{Cu}$ transition. These previous ship-

96 based efforts provided a health of information with regard to the vertical structure of the

97 MBL and associated clouds. However, they were primarily conducted in a fairly small

98 region and focused on studying one specific cloud type For example, the First

99 International Satellite Cloud Climatology Project (ISCCP) Regional Experiment (FIRE;

100 Albrecht et al. 1988) focused on Sc and cirrus cloud regimes, the Tropical Instability

101 Wave Experiment (TIWE; Albrecht et al. 1995b) focused on the trade wind Cu boundary

102 layer structure, and during the Atlantic Stratocumulus Transition Experiment (ASTEX;

103 Albrecht et al., 1995a) a transition region in which $\mathrm{Cu}$ form beneath Sc was observed.

104 Albrecht et al. (1995b) compared the large-scale forcing and thermodynamic profiles

105 from these three field experiments and concluded that the increase in sea surface

106 temperature (SST) is important in the thinning of the Sc. The same study provided

107 evidence that the boundary layer structure and the associated transition from $\mathrm{Sc}$ to $\mathrm{Cu}$

108 may be more complicated than originally thought. More recently, Jones et al. (2011)

109 examined in detail the coupled and decoupled boundary layers in the Variability of the

110 American Monsoon Systems (VAMOS) Ocean-Cloud-Atmosphere-Land Study Regional

111 Experiment (VOCALS-REx; Wood et al., 2011). One of the major findings in Jones et al,

1122011 is that the difference between MBLH and the lifting condensation level (LCL) best

113 predicts decoupling.

114 Previous numerical studies have demonstrated that the systematic decoupling is mainly

115 driven by the increasing surface latent heat flux (LHF) as a response to the increasing 
116 entrainment due to the warmer SST (e.g. Bretherton and Wyant, 1997, Sandu and Stevens,

117 2011). The subsequent Sc breakup was explained as a result of the further increase of the

118 SST that causes the $\mathrm{Cu}$ to become deeper and more vigorous, penetrating farther into the

119 inversion and entraining more dry air from above the inversion (Wyant et al., 1997;

120 Sandu and Stevens, 2011). Although numerical studies have advanced our knowledge of

121 MBL structure and clouds, simulations have usually simplified the problem by assuming

122 the constant divergence and free-tropospheric lapse rates (Bretherton and Wyant, 1997),

123 but neither assumption is supported by observations.

124 There are noticeable discrepancies between idealized model simulations and

125 observational findings. For instance, the dominant effect of the LHF on MBL decoupling

126 was not observed in VOCAL-REx (Jones et al. 2011). Additionally, the assumption of a

127 constant free-atmosphere lapse rate might introduce biases because MBLH and boundary

128 layer mixing ratios are very sensitive to above-inversion features (Albrecht 1984;

129 Krueger et al. 1995). At the same time, the availability of comprehensive, long-term

130 observations that document the gradual MBL decoupling and Sc-to- $\mathrm{Cu}$ transitions is

131 limited.

132 The recent MAGIC field campaign provided high resolution, profiling observations, from

133 the coast of California to Honolulu for over 200 days. The collected dataset is the most

134 extensive direct, long-term, intra-seasonal set of measurements of MBL structure and

135 cloud evolution from $\mathrm{Sc}$ to $\mathrm{Cu}$ over large downwind regions. Here, we investigate the

136 potential of the dataset in advancing our understanding of the systematic MBL

137 decoupling and Sc breakup to be compared with and constrain the modeling studies. 
138 The remaining of the manuscript is organized as follows. Brief descriptions of the 139 MAGIC field campaign and of the AMF-2 instruments are provided in Section 2, and the 140 methodology used for this study is introduced in Section 3. Results are presented in

141 Section 4, and a summary of these results and plans for future work are presented in 142 Section 5.

\section{OBSERVATIONS}

147 The MAGIC field campaign (http://www.arm.gov/sites/amf/mag/) deployed the US 148 Department of Energy (DOE) Atmospheric Radiation Measurement (ARM) Mobile 149 Facility 2 (AMF2) on the commercial cargo container Horizon Spirit (Fig. 1a). The 150 MAGIC transect is very near the line from the coast of California to the equator $\left(35^{\circ} \mathrm{N}\right.$, $151125^{\circ} \mathrm{W}$ to $1^{\circ} \mathrm{S}, 173^{\circ} \mathrm{W}$ ) that was chosen by modelers to compare model results for the 152 Global Energy and Water Experiment (GEWEX) Cloud System Studies (GCSS) Pacific 153 Cross-section Intercomparison (GPCI) study, in which more than twenty climate and 154 weather-prediction models participated (Teixeira et al., 2011). Thus, MAGIC with its 155 unprecedented, intra-seasonal, high-resolution ship-based observations is expected to 156 provide constraint, validation, and support for the aforementioned modeling efforts and at 157 the same time contribute in improving our understanding of the Sc-to- $\mathrm{Cu}$ transition along 158 this GPCI transect. 
159 From October, 2012 through September, 2013, the Spirit completed 20 round trips 160 between Los Angeles, California, and Honolulu, Hawaii. Each trip is called a "leg", and 161 legs are numbered sequentially as "LegxxA" for the trips from Los Angeles to Honolulu 162 and "LegxxB" for the return trips (Fig. 1b). During the legs from Los Angeles, the Spirit 163 traveled at $\sim 21 \mathrm{kts}\left(\sim 10.5 \mathrm{~m} \mathrm{~s}^{-1}\right)$ and covered the $4100 \mathrm{~km}$ distance in 4.5 days. The Spirit 164 returned to Los Angeles at $\sim 16 \mathrm{kts}\left(\sim 8 \mathrm{~m} \mathrm{~s}^{-1}\right)$, making the trip in approximately 6.5 days 165 (the lower speed resulting in lower fuel costs and allowing the ship to remain on a two166 week schedule; Lewis et al., 2012). The departure and arrival times of MAGIC legs are 167 listed in Appendix A. Two technicians associated with the MAGIC campaign lived on 168 board the Spirit during the deployment to maintain the instrumentation, launch 169 radiosondes, and perform other tasks.

173 The AMF2 contains a state-of-the-art instrumentation suite and was designed to operate 174 in a wide range of climate conditions and locations, including shipboard deployments. 175 The AMF2 was located on the bridge deck of the Spirit, approximately $16 \mathrm{~m}$ above sea 176 level (ASL). The primary AMF2 instruments used in the current study are 1) a Ka-band 177 ARM Zenith Radar (KAZR), 2) a laser ceilometer, 3) a Vaisala weather station, 4) a 178 inertial navigational location and attitude system (NAV), 5) the Marine Meteorological 179 System (MARMET) installed on the mast of the Spirit approximately $27 \mathrm{~m}$ above sea 180 level and an Infrared Sea-surface temperature Autonomous Radiometer (ISAR), and 6) 
181 radiosondes (four or eight per day). AMF2 also contained a motion-stabilized W-band

182 radar, a radar wind profiler, a broadband and spectral radiometer suite, aerosol

183 instrumentation, and other instruments. The operational status of all instruments during

184 the campaign is summarized in Appendix B. There were some time periods when the

185 KAZR was not acquiring data for various reasons (e.g., installation, power outages, etc.),

186 but KAZR measurements were obtained for all of Leg03A through Leg08B, Leg11, and

187 Leg14A through Leg17B. The analyses presented here are based on these data, in total 22

188 transits between California and Hawaii through the Sc-to- $\mathrm{Cu}$ transition region comprising

189 more than 3000 hours. The data are separated into two seasons, the warm season: Leg11

190 and Leg14 to Leg17 (May 25 to June 6, and July 7 to August 29, 2013), and the cold

191 season: Leg03 to Leg08 (October 6 to December 27, 2012).

192

193

194

2.2.1 Ka-band ARM Zenith Radar (KAZR)

195

196 The KAZR, formerly known as the millimeter wavelength cloud radar (MMCR, Moran et

197 al., 1998), is a 35-GHz profiling Doppler radar that retrieves information on the vertical

198 distribution of the hydrometeors in the atmospheric column. Due to its short wavelength

199 (8.6 mm), the KAZR has sufficient sensitivity to detect MBL clouds with little

200 attenuation under moderate drizzle conditions. The KAZR might fail to detect very thin

201 liquid clouds and it can provide inaccurate hydrometeor-layer heights during heavy

202 precipitation because of severe radar signal attenuation (Matrosov, 2007), but because a

203 ceilometer was used (Section 2.2.2) and because there was very little heavy precipitation 
204 during MAGIC, these issues should have little effect on the results of this study. The 205 KAZR utilizes a new digital receiver that provides higher temporal (less than 2 s) and 206 spatial $(30 \mathrm{~m})$ resolution than the MMCR (Widener et al., 2012). It is unaffected by 207 Bragg scattering and has small antennas with narrow beamwidths as well as limited 208 sidelobes (Kollias et al., 2007). During MAGIC, the KAZR was configured to have 209 temporal resolution of about $0.4 \mathrm{~s}$ to oversample the ship motion, thus enabling 210 compensation of the effects of this motion on the radar observables during data post-

211 processing. In this study, all KAZR measurements have been averaged over $4 \mathrm{~s}$, which 212 allows for the detection of small-scale $\mathrm{Cu}$.

\subsubsection{Ceilometer}

216 A ceilometer (Vaisala model CT25K) operating at a wavelength of $910 \mathrm{~nm}$ was used to 217 detect the base heights of clouds. The ceilometer's range resolution was $10 \mathrm{~m}$, and its 218 temporal resolution was near $16 \mathrm{~s}$ for Leg03 and Leg04 and $3 \mathrm{~s}$ for the other legs. In order 219 to maintain the 4-s temporal resolution, it is assumed that each reported base height is 220 representative of the entire original time period.

225 A Vaisala weather station WXT-520 installed as part of a suite of meteorological 226 instruments associated with the Aerosol Observing System of the AMF2 (AOSMET) 
227 measured rain intensity at $1 \mathrm{~s}$ resolution which was used to detect the presence of 228 precipitation reaching the ground (see Section 3c).

232 NAV provided ship location and attitude with a temporal resolution of $1 \mathrm{~s}$ during the

233 period between November 3 and December 3, 2012 (Leg05A to Leg07A), and $0.1 \mathrm{~s}$ for

234 the rest of the deployment. As all macroscopic data are averaged over $4 \mathrm{~s}$, both temporal 235 resolutions are sufficiently accurate for the present comparisons. (MARFLUX) data sets

240 The MARMETX data set (http:/www.arm.gov/campaigns/amf2012magic/) contains 241 standard surface meteorological parameters measured by the MARMET: temperature (T), 242 pressure $(\mathrm{P})$, relative humidity $(\mathrm{RH})$, and apparent and true wind speed and direction; and 243 the sea-surface skin temperature (SSST) measured by the ISAR (with an accuracy of 244 better than $0.1^{\circ} \mathrm{C}$ ). MARFLUX (http://www.arm.gov/campaigns/amf2012magic/)

245 contains the surface fluxes of moisture and sensible and latent heat calculated by the 246 TOGA-COARE air-sea flux algorithm (Fairall et al., 1996) using the MARMETX 247 variables. Both MARMETX and MARFLUX have a time resolution of $1 \mathrm{~min}$. 
251 Standard radiosondes (Vaisala model MW-31, SN E50401) were launched every 6 h to 252 measure vertical profiles of the thermodynamic state of the atmosphere $(\mathrm{T}, \mathrm{P}, \mathrm{RH}$, and 253 wind speed and direction). During Leg14, which occurred in July 2013, launches were 254 made every $3 \mathrm{~h}$ to provide a more detailed picture of the atmospheric structure. Only 255 soundings providing measurements as high as $15 \mathrm{~km}$ were used in this study (389 in all). 256 The radiosondes collected data every $2 \mathrm{~s}$ during their ascent, providing a typical vertical 257 resolution of $10 \mathrm{~m}$ in the troposphere. However, owing to the limited launching frequency 258 (four to eight per day), sounding data can be interpolated to higher-resolution time steps 259 with only limited confidence.

\section{METHODOLOGY}

\subsection{Hydrometeor mask}

266 A hydrometer mask was applied to the raw KAZR reflectivity measurements to identify

267 the radar range gates that contain appreciable returns from hydrometeors. Following 268 Rémillard et al. (2012), this mask uses the algorithm of Hildebrand and Sekhon (1974) 269 and a two-dimensional (time-height) filter to identify the number of hydrometeor layers

270 in the atmospheric column and their corresponding boundaries. The lowest hydrometeor 271 boundary is not necessarily the cloud base because the KAZR cannot distinguish cloud 272 drops from precipitation particles below the cloud base. 
276 To obtain cloud boundaries, the hydrometeor mask is combined with the ceilometer277 generated time series of cloud-base height. The ceilometer cloud-base heights are binned 278 to the KAZR spatial resolution, with an uncertainty of less than $15 \mathrm{~m}$ (the KAZR has 279 range resolution of $30 \mathrm{~m}$ ). Examples of the KAZR hydrometeor mask along with first 280 ceilometer-derived cloud-base heights for Leg04A and Leg04B are shown in Fig. 2. The 281 combination of the KAZR and the ceilometer is sufficient to characterize cloud fraction 282 (CF) and layering in the lower troposphere (i.e., $<\sim 3 \mathrm{~km}$ ), although hydrometeor 283 occurrence in the upper troposphere is probably underestimated because the maximum 284 operational range of the ceilometer is $5-6 \mathrm{~km}$. However, as the analysis here pertains to 285 MBL clouds, this underestimation should not introduce any biases.

286 Cloud tops for each hydrometeor layer throughout the troposphere are determined using 287 the KAZR-derived hydrometeor mask. In liquid clouds, KAZR reflectivity measurements 288 below the first cloud-base height determined by the ceilometer are used to characterize 289 precipitation (see next section). If no ceilometer data are available, no KAZR data below $290300 \mathrm{~m}$ are used, since they often contain artifacts (especially when no precipitation is 291 present). In cases when the first ceilometer-derived base height is $100 \mathrm{~m}$ or more less 292 than the first KAZR-defined hydrometeor base height, the two clouds are considered 293 independent, with the first cloud-top height undetermined; otherwise the first KAZR 294 hydrometeor top is considered to be the first cloud top. 
296 Once the cloud boundaries are determined, each time-height cluster of KAZR echoes 297 with more than 25 connected pixels (in time-height space) is considered to be a cloud 298 entity. In order to obtain realistic bases of multiple-layer cloud entities, the bases of the 299 second cloud level are further smoothed according to the ceilometer-derived base heights.

300 KAZR echoes below the newly defined cloud bases are neglected. Each cloud entity is 301 categorized into one of four types based on its average base and top heights (Table 1, see

302 Fig. 3a as an example): high-level, mid-level, MBL, or cumulus congestus and deep 303 convective. High-level clouds have average base heights of at least $6 \mathrm{~km}$. Mid-level 304 clouds have average base heights between $3 \mathrm{~km}$ and $6 \mathrm{~km}$. MBL clouds have average 305 base heights and top heights less than $3 \mathrm{~km}$, or have undetermined average top heights.

306 Cumulus congestus and deep convective clouds have average base heights less than $3 \mathrm{~km}$ 307 but average top heights of at least $3 \mathrm{~km}$. The statistical results of cloud properties 308 presented in this study are not sensitive to the specific values chosen for the thresholds.

309 An MBL cloud layer is detected if more than $10 \%$ of cloud bases are measured over a 310 continuous range of heights during one hour (a one-gate gap is allowed). The cloud bases 311 here refer to the first and second ceilometer-derived bases and the first three 312 hydrometeor-mask bases.

313 As the focus of this study is MBL clouds, emphasis is placed on these clouds, which are 314 further divided into three subtypes: stratocumulus $(\mathrm{Sc})$, cumulus $(\mathrm{Cu})$, and indeterminate 315 (e.g., Figs. 3b and 3c). Sc are low clouds composed of an ensemble of individual 316 convective elements that together assume a layered form (Wood, 2012), whereas $\mathrm{Cu}$ 317 clouds are separate convective elements. The difference between $\mathrm{Sc}$ and $\mathrm{Cu}$ in this study 
318 is based on their time durations: a cloud is defined as Sc if it lasts more than $20 \mathrm{~min}$, and

319 as $\mathrm{Cu}$ if its duration is less than $20 \mathrm{~min}$. Sc clouds are also required to have a narrow

320 cloud top height distribution that is restricted by a specific standard deviation threshold

321 that depends on its duration (see Table 1 for details). The remaining MBL cloud clusters

322 make up the subtype 'indeterminate'. Because of the limited nature of the MAGIC

323 observations (1D in distance/time and height), these cloud types are not mutually

324 exclusive.

325 Because of their ship-based origin, the cloud macroscopic data for each leg depend on

326 both time and location (e.g., Figs. 1,2). To account for slight ship-course deviations

327 between different legs (Fig. 1b), all of the cloud macroscopic data are binned to a uniform

328 great-circle route with 40-m resolution (the approximate distance covered by the ship in 4

329 s) in order to examine the evolution of cloud properties along this representative great-

330 circle transect. Finally, all the cloud macroscopic data are averaged over $36-\mathrm{km}$ (the

331 approximate distance covered by the ship in $1 \mathrm{hr}$ ) and converted to the corresponding

332 latitude along the great-circle route. The frequency of occurrence of MBL cloud every

333 36-km are considered to represent the $\mathrm{CF}$ over that area and are referred to as $\mathrm{CF}_{36}$ in this 334 paper.

339 heights, surface rainfall occurrence from the weather stations, and $0^{\circ} \mathrm{C}$ isotherm heights 
340 derived from interpolated radiosonde data are used characterize precipitation. KAZR

341 echoes are classified as either cloud or precipitation; no attempt is made to distinguish ice

342 hydrometeors from liquid cloud drops or precipitation. Because the cloud-base heights

343 are determined from the ceilometer data, every KAZR echo below the first cloud-base

344 height is classified as precipitation. The ceilometer quality control flag was checked to

345 ensure that no water was present on the ceilometer window (which would occur in the

346 case of intense precipitation reaching the surface), since this would strongly attenuate the

347 signal and result in inaccurate readings.

348 Precipitation is classified into five types (Table 2): virga, drizzle, warm rain, cold rain, 349 and deep convective rain (e.g., Fig. 3d). Precipitation that is not detected at the surface is

350 either virga or drizzle. The distinction between the two is based on the detection of

351 KAZR echoes in the lowest range gate (around $120 \mathrm{~m}$ ASL before Leg11A, and $240 \mathrm{~m}$

352 ASL for the later legs): virga is defined as precipitation that is detected at least $50 \mathrm{~m}$

353 below the ceilometer cloud base and does not reach the lowest KAZR range gate,

354 whereas drizzle is detected at the KAZR lowest range gate. This distinction provides a

355 qualitative indicator of light rain intensity and indicates the portion of the subcloud layer

356 affected by evaporation. Under this proposed definition only rain that falls through a

357 cloud and not that from the side of a cloud could be considered virga. Precipitation is

358 defined as warm (cold) rain when it is detected at the surface and when the first KAZR-

359 derived cloud top is above $3 \mathrm{~km}$ but lower (higher) than the $0^{\circ} \mathrm{C}$ isotherm height,

360 regardless of the ceilometer-derived cloud-base height. Precipitation is defined as deep

361 convective rain when it is detected at the surface and when the radar reflectivity at the

362 lowest range gate is greater than $0 \mathrm{dBZ}$ and also greater than that at the first KAZR 
363 cloud-top height. Similar to the cloud macroscopic data, the precipitation data for each

364 leg are averaged over 36-km along the great-circle route.

368 Radiosonde data are used to determine the thermodynamic structure of the lower

369 atmosphere. Emphasis in this study is placed on identifying the inversion and transition

370 layers, which are closely associated with MBL stratification and MBL clouds. The

371 inversion layer is defined as all levels around the maximum increase of temperature with

372 height that occurs between $500 \mathrm{~m}$ and $3 \mathrm{~km}$ that have an increase of temperature and a

373 decrease in water vapor mixing ratio $(r)$ with height (see Rémillard et al., 2012 for more 374 details).

375 Following the algorithm of Yin and Albrecht (2000), a parameter $\mu$ is defined for each

376 level below the inversion base in terms of the potential temperature $(\theta)$ and $r$ :

$$
\mu=-\left(\frac{\partial \theta}{\partial P}-\frac{0.608 \theta}{1+0.608 r} \frac{\partial r}{\partial P}\right)
$$

378 and the transition layer is defined whenever the maximum value of $\mu$ is positive and 379 consists of all levels below the base of the inversion at which $\mu$ is greater than 1.3 times 380 its mean value over the entire region below the inversion. Examples of the sounding381 derived inversion and transition layers under conditions of broken $\mathrm{Cu}$ and overcast $\mathrm{Sc}$ are 382 illustrated in Figs. 4a and 4b, respectively. 
383 The sounding data for each vertical profile are smoothed prior to any analysis using only

384 the next-nearest points to remove small-scale variability and to provide smooth local

385 gradients. To preserve the features of the transition and inversion layers, a layer-by-layer

386 averaging procedure is performed when averaging various profiles together (Augstein et

387 al., 1974; Yin and Albrecht, 2000; Rémillard et al., 2012). Between the surface and 3 km,

388 the profiles are broken into 5 layers: the layer below the transition, the transition layer,

389 the layer between the transition and the inversion, the inversion layer, and the layer above

390 the inversion. Each layer is averaged separately using a normalized height coordinate

391 (from 0 to 1 ) and is combined with other layers using the averaged base and top heights

392 of the layers as the height coordinate.

393 The difference between equivalent potential temperature at the inversion top ( $\theta_{\text {e(inv_top) }}$ )

394 and base $\left(\theta_{\text {e(inv_base) }}\right)$,

$$
\Delta \theta_{e}=\theta_{e\left(i n v_{-} t o p\right)}-\theta_{e\left(i n v_{-} \text {base }\right)},
$$

396 provides information on the stability of the MBL: lower values of $\Delta \theta_{\mathrm{e}}$ indicates greater

397 cloud-top entrainment instability because the entrained air, after becoming saturated,

398 would be more negatively buoyant and would continue to sink further (Lilly, 1968;

399 Deardorff, 1980). Additionally, numerical calculations demonstrate that the entrainment

400 rate increases abruptly when $\Delta \theta_{\mathrm{e}}$ decreases below a critical value (Deardorff, 1980).

401 Approximately $10 \%$ of the profiles contained an artificial peak in water vapor mixing

402 ratio immediately above Sc due to the wet-bulb effect of the radiosondes; when this

403 occurred, $\theta_{\text {e(inv_top) }}$ was replaced by the value of $\theta_{\mathrm{e}}$ immediately below this peak. 
404 The inversion strength is quantified using the lower-tropospheric stability (LTS; Klein 405 and Hartmann, 1993) and by the Estimated Inversion Strength (EIS; Wood and 406 Bretherton, 2006). LTS is defined as the difference between the potential temperature at $407700 \mathrm{hPa}\left(\theta_{700}\right)$ and that at the surface $\left(\theta_{\text {surface }}\right)$,

$$
L T S=\theta_{700}-\theta_{\text {surface }}
$$

409 EIS is defined as

$$
E I S=L T S-\Gamma_{m}^{850}\left(Z_{700}-L C L\right)
$$

411 where $\Gamma_{m}^{850}$ is the moist adiabat at $850 \mathrm{hPa}, Z_{700}$ is the $700 \mathrm{hPa}$ height, and $L C L$ is the 412 lifting condensation level. The $L C L$ can be approximated by Epsy's formula (Bohren and 413 Albrecht, 1998) in terms of the surface values of the air temperature $\left(T_{s}\right)$, dew point 414 temperature $\left(T_{\mathrm{d}}\right)$, dry adiabatic lapse rate $\left(\Gamma_{\mathrm{d}}\right)$, and pseudo-adiabatic lapse rate $\left(\Gamma_{\mathrm{s}}\right)$ as

$$
L C L=\frac{T_{s}-T_{d}}{\Gamma_{d}-\Gamma_{s}} ;
$$

416 numerically, the value of $L C L$ (in $\mathrm{m}$ ) is approximately 125 times the difference $T_{\mathrm{s}}-T_{\mathrm{d}}$ (in 417 K). EIS, and previously LTS, have been shown to correlate well with the occurrence of 418 the Sc-to-Cu transition (Wyant et al., 1997); however, EIS is a more physically based 419 quantity as it accounts for the influence of the accumulated static stability between the 420 inversion and the 700-hPa level (Wood and Bretherton, 2006).

421 To derive the statistics, all the sounding data are averaged over $36-\mathrm{km}$ and converted to 422 corresponding latitude along the great-circle route. As the statistics of the inversion layer 423 presented below are based primarily on measurements from radiosondes, which were 
424 launched four (eight) times every day (see Section 2.2), each sounding profile is assumed

425 to be representative of the atmospheric structure over the $6 \mathrm{~h}(3 \mathrm{~h})$ time around the 426 sounding. Due to the sparseness of these data, these statistics might not be as robust as

427 those derived from the radar, but nonetheless they are expected to accurately represent 428 the observed trends.

433 The commencement of the systematic MBL decoupling (DE) and Sc breakup (CB) 434 towards Hawaii has been determined for each leg in order to better understand their 435 triggering factors. At each location, the difference in the mean water vapor specific 436 humidity $\left(q_{\mathrm{v}}\right)$ between the bottom $25 \%$ of the MBL and the top $25 \%$ of the MBL is 437 calculated:

$$
\Delta q=q_{v}(\text { bot })-q_{v}(t o p)
$$

439 This quantity is related to $\Delta z_{b}$, the difference in the Sc cloud bases formed below the 440 inversion $(\mathrm{zb})$ and the LCL:

$$
\Delta z_{b}=z_{b}-L C L
$$

442 where $\mathrm{z}_{\mathrm{b}}$ is calculated as the maximum MBL cloud bases (averaged over $36 \mathrm{~km}$ ) within 443 four degrees longitude surrounding each radiosonde. The linear relationship between $\Delta \mathrm{q}$ 444 and $\Delta \mathrm{z}_{\mathrm{b}}$ (Figure 5a) with the slope (276 m kg g-1) and intercept (200 m) comparable to 445 those found in Jones et al. (2011), demonstrate that $\Delta \mathrm{q}$ is a robust proxy for $\Delta \mathrm{zb}$. Some 
446 scatter is introduced since $\Delta \mathrm{q}$ comes from a single profile while $\Delta \mathrm{zb}$ is an averaged 447 maximum value. Biases might be introduced when no Sc was detected near a radiosonde 448 or when MBLH was not well represented due to the very shallow MBL near the coast of 449 California. Thus only those radiosondes within 1.5 standard deviations of the least square 450 fit and that to the west of $123^{\circ} \mathrm{W}$ were used (336 in total). A threshold of $\Delta \mathrm{q}>1.5 \mathrm{~g} \mathrm{~kg}^{-1}$ 451 (or equivalently $\Delta z_{i}>600 m$ ) is found appropriate to capture the systematic decoupled 452 MBL (Fig. 5b). Compared to the threshold of $\Delta \mathrm{q}>0.5 \mathrm{~g} / \mathrm{kg}\left(\Delta \mathrm{z}_{\mathrm{i}}>150 \mathrm{~m}\right)$ for all kinds of 453 decoupling in VOCAL-REx (Jones et al., 2011), the systematic decoupling showed much 454 stronger moisture stratification below the inversion. Subsequently, the DE during each 455 transect is then defined as the most easterly profile of a group of profiles with continuous 456 decoupling features $\left(\Delta \mathrm{q}>1.5 \mathrm{~g} \mathrm{~kg}^{-1}\right)$. Between the detected and the nearest east radiosonde 457 launches, the $\Delta \mathrm{q}$ criteria for decoupling is replaced by the difference of the instantaneous 458 ceilometer-derived cloud bases height and LCL calculated by the ship-measured T and 459 RH. Compared to the systematic decoupling, the weak decoupled MBL is also studied in 460 this paper and is defined as the MBL with $\Delta \mathrm{z}_{\mathrm{i}}>150 \mathrm{~m}$ (Consistent with Jones et al., 2011). 461

462 Due to mesoscale influences, $\mathrm{CF}_{36}$ sometimes shows variability and does not represent 463 well the major cloud evolution along the transect. To reduce the effects of mesoscale 464 variability and to more objectively capture $\mathrm{CB}$, the frequency of occurrence of the MBL 465 clouds was averaged over $108 \mathrm{~km}\left(\mathrm{CF}_{108}\right)$. $\mathrm{CB}$ is then defined as the location along the 466 transect from California to Hawaii where $\mathrm{CF}_{108}$ decreased from being greater than $80 \%$ 467 for at least three continuous points $(324 \mathrm{~km})$ east of $130^{\circ} \mathrm{W}$ to being less than $15 \%$. 468 Values of CFMBL were generally not sensitive to the above criteria. No cloud breakup 
469 points are determined if values of CFMBL east of $130^{\circ} \mathrm{W}$ were not sufficiently high 470 (Leg06A, Leg06B, Leg08A, Leg08B, and Leg17B) or if they did not become sufficiently 471 low (Leg15B). Those legs are associated with either mid-latitude or tropical cyclones, or 472 very strong cloud outbreaks thus not represent the Sc breakup in a general sense, and 473 their exclusion helps to elucidate the more general aspects of the transition.

474

475

476

477

478

479 The results presented below are separated into two sections. The first section includes 480 general statistical description of MBL clouds, precipitation, thermodynamics and their 481 seasonal behavior. The second section focuses on the study of MBL systematic 482 decoupling and cloud breakup.

\section{RESULTS} seasonal behavior. The second section focuses on the study of MBL systematic

4.1 General statistics of MBL clouds, precipitation and thermodynamics

\subsubsection{Cloud and Precipitation Occurrence}

The fraction of time that the four main cloud types defined in Section 3.2 are detected (i.e., their frequencies of occurrence over individual legs) is shown in Figure 6a. MBL clouds are by far the most frequently observed cloud type, and all other types contribute less than $10 \%$ to the total observed hydrometeor occurrence in the column. The frequency of occurrence of MBL clouds has a broad maximum near $75 \%$ between $125^{\circ} \mathrm{W}$ and 
$491135^{\circ} \mathrm{W}$ and decreases steadily to values near $20 \%$ near Hawaii. Lower values of MBL

492 cloud occurrence are also observed near the coast of California. The frequency of 493 occurrence of precipitation from MBL clouds (Fig. 6b) exhibits a very similar pattern to 494 that of MBL cloud occurrence.

495 A seasonal breakdown of MBL cloud occurrence is shown in Fig. 6c. The frequencies of 496 occurrence of MBL clouds in the warm season and the cold season exhibit generally 497 similar spatial patterns. During the warm season a broad maximum near of $90 \%$ between $498 \sim 122^{\circ} \mathrm{W}$ and $\sim 132^{\circ} \mathrm{W}$ is observed, whereas that during the cold season a maximum near 499 of $70 \%$ between $\sim 128^{\circ} \mathrm{W}$ and $\sim 132^{\circ} \mathrm{W}$ is observed. On average, the observed MBL cloud 500 occurrence in the warm season is $20-40 \%$ higher than that observed in the cold season.

501 As expected, the frequency of occurrence of precipitation (Fig. 6d) is also generally 502 higher during the warm season than during the cold season. During the warm season 503 precipitation exhibits a maximum of $\sim 80 \%$ between $\sim 123^{\circ} \mathrm{W}$ and $\sim 131^{\circ} \mathrm{W}$, but during the 504 cold season the broad maximum, at $\sim 55 \%$ is observed between $\sim 128^{\circ} \mathrm{W}$ and $\sim 136^{\circ} \mathrm{W}$. In 505 contrast to the relatively high frequency of occurrence of clouds during the warm season 506 east of $124^{\circ} \mathrm{W}$, the corresponding frequency of occurrence of precipitation decreases 507 rapidly. This might be attributed to the presence of thin clouds at this region (average 508 thickness of $180 \mathrm{~m}$ east of $124^{\circ} \mathrm{W}$ compared to $300 \mathrm{~m}$ west of $124^{\circ} \mathrm{W}$ ).

509 The mean cloud-base height $\left(\mathrm{H}_{\mathrm{b}}\right.$, Fig. 6e) and mean cloud-top height $\left(\mathrm{H}_{\mathrm{t}}\right.$, Fig. 5f) of the 510 lowest cloud layer show little seasonal variability except for the regions east of $125^{\circ} \mathrm{W}$. 511 Mean values of $\mathrm{H}_{\mathrm{b}}$ increase gradually from $0.6 \mathrm{~km}$ near the coast of California to $1 \mathrm{~km}$ 512 near $135^{\circ} \mathrm{W}$ and remain at around $1 \mathrm{~km}$ further west but exhibit increasing fluctuations, 
513 reflecting the intermittent presence of small-scale $\mathrm{Cu}$ clouds below the $\mathrm{Sc} . \mathrm{H}_{\mathrm{t}}$ values are

514 on average $230 \mathrm{~m}$ greater than those of $\mathrm{H}_{\mathrm{b}}$ and also exhibit fluctuations west of $135^{\circ} \mathrm{W}$.

515 East of $125^{\circ} \mathrm{W}$ we found the most noticeable difference in $\mathrm{H}_{\mathrm{b}}$ and $\mathrm{H}_{\mathrm{t}}$ between the warm

516 and cloud season. The lower $\mathrm{H}_{\mathrm{b}}$ east of $125^{\circ} \mathrm{W}$ during the warm season might be

517 attributed to the stronger coastal upwelling that results to lower SST (Fig. 6g), while the

518 higher $\mathrm{H}_{\mathrm{t}}$ east of $125^{\circ} \mathrm{W}$ during the cold season might be attributed to a frontal system

519 that occurred during Leg06B and a low-pressure system during Leg07B.

520 Most of the precipitation produced by MBL clouds is in the form of virga (Fig. 6h). Virga

521 is the dominant precipitation type over the entire transect except for the region east of

$522126^{\circ} \mathrm{W}$. The virga frequency of occurrence peaks at $40 \%$ near $130^{\circ} \mathrm{W}$, whereas that of

523 drizzle (precipitation that reaches the surface) exhibits a sharp maximum of more than $30 \%$

524 near $124^{\circ} \mathrm{W}$, contributing to the noticeable peak of precipitation frequency at this location

525 (Fig. 6b and Fig. 6d). The increasing frequency of occurrence virga and decreasing

526 frequency of occurrence of drizzle from $124^{\circ} \mathrm{W}$ to $130^{\circ} \mathrm{W}$ (Fig. 6h) might be attributed to

527 the increasing cloud-base height (Fig. 6e) caused by the warmer SST (Fig. 6g) away from

528 the California coast. The low frequencies of occurrence (less than 10\%) of both virga and

529 drizzle near Hawaii are consistent with the low frequency of occurrence of MBL clouds

530 there (Fig. 6a, 6b, 6c). At the same time, the low frequencies of occurrence of both virga

531 and drizzle east of $124^{\circ} \mathrm{W}$ is associated with the presence of thinner clouds in that region

532 (Fig. 6e, 6f) and to the higher in-cloud cloud droplet concentrations. The mean surface

$533 \mathrm{CCN}$ at $119^{\circ} \mathrm{N}$ is on averaged $150 / \mathrm{cm}^{3}$ higher than that around $122^{\circ} \mathrm{W}$ (Lohmann and

534 Feichter, 2005). 
537 The mean and seasonal values of MBLH and EIS (Eq. 4) along the MAGIC transect are 538 shown in Fig. 7. The mean MBLH (Fig. 7a) generally increases from California to 539 Hawaii, with slightly lower values in the warm season. The largest differences in MBLHs 540 between the warm season and cold season are observed east of $125^{\circ} \mathrm{W}$, with those 541 observed during the cold season being nearly twice as high as those during the warm 542 season near the coast of California. The low MBLH east of $125^{\circ} \mathrm{W}$ during the warm 543 season results in thin clouds (see section 4.1.1) and correspondingly a low frequency of 544 precipitation there (Fig. 6d). The deeper MBL during the cold season is consistent with 545 the high $\mathrm{H}_{\mathrm{t}}$ (Fig. 6f), which might be due to synoptic influences (see Section 4.1.1). The 546 decrease in $\mathrm{MBLH}$ between $145^{\circ} \mathrm{W}$ and $150^{\circ} \mathrm{W}$ can also attributed to synoptic influences

547 and is discussed below. The trend in MBLH along the MAGIC transect (Fig. 7a) follows 548 that of $\mathrm{H}_{\mathrm{t}}$ (Fig. $6 \mathrm{f}$ ) east of $135^{\circ} \mathrm{W}$, indicating the capped feature of the MBL, while values 549 of $\mathrm{H}_{\mathrm{t}}$ west of $135^{\circ} \mathrm{W}$ are generally less than those of MBLH, indicating MBL decoupling 550 and $\mathrm{Cu}-$ under-Sc cloud regimes.

551 The mean EIS (Fig. 7b) decreases gradually from $9 \mathrm{~K}$ near the coast of California to 552 around $2 \mathrm{~K}$ near Hawaii, with values in the warm season being 1-3 $\mathrm{K}$ higher and those 553 during the cold season 1-3 K lower, the differences decreasing toward Hawaii. EIS shows 554 strong linear relationship with SST along the transect (figure not shown), while in terms 555 of the seasonal variability, leg-mean EIS is mainly determined by the leg-mean potential 556 temperature at $700 \mathrm{hPa}$ (Fig. 7c). This quantity exhibits a larger seasonal variability, 557 ranging from $7 \mathrm{~K}$ to $11 \mathrm{~K}$ among different legs due to the subsidence of the dry warm air 
558 from above the inversion layer, while $\theta_{\text {surface, }}$ which depends largely on SST, varies less

559 than $1 \mathrm{~K}$ between seasons.

560 It is likely that the seasonal variability of EIS (Fig. 7b) contributes to the seasonal

561 variability in the frequency of occurrence of MBL clouds (higher amount of MBL cloud

562 in the warm season and lower in the cold season), consistent with the conclusion of Wood

563 and Bretherton (2006) that stratus cloud fraction is largely determined by EIS. The higher

564 frequency of occurrence of MBL clouds during the warm season when EIS was higher

565 (Fig. 6c) reflects the importance of the strong warm-season large-scale Hadley cell (Xu

566 and Cheng, 2013) that brings dry warm air downward, leading to higher values of $\theta_{700}$

567 (Fig. 7c).

568

$569 \quad$ 4.1.3 Sc and $\mathrm{Cu}$ occurrence and thermodynamic features

570

571 Frequencies of occurrence of the two important MBL cloud types, $\mathrm{Sc}$ and $\mathrm{Cu}$, are 572 examined in this section. Statistics of total and seasonal occurrence of $\mathrm{Sc}$ and $\mathrm{Cu}$ are 573 shown in Fig. 8. The frequency of occurrence of Sc attains a broad maximum near $60 \%$

574 between $125^{\circ} \mathrm{W}$ and $135^{\circ} \mathrm{W}$, and decreases to near $0 \%$ near Hawaii. The decrease in

575 frequency of occurrence of Sc is not uniform along the MAGIC transect, and is greatest

576 near $137^{\circ} \mathrm{W}$ and near $144^{\circ} \mathrm{W}$, consistent with the sharp decreases in MBL cloud

577 occurrence (Fig. 6a) at these locations. In contrast, the frequency of occurrence of $\mathrm{Cu}$ is

578 always low, but steadily increases from near 5\% near the coast of California to over $10 \%$

579 near Hawaii. Sc are more frequently observed during the warm season than during the 580 cold season, while the occurrence of $\mathrm{Cu}$ is almost the same for both seasons, with slightly 
581 more frequent cold-season $\mathrm{Cu}$ close to the coast of California and slightly more warm582 season $\mathrm{Cu}$ close to Hawaii.

583 The comparison between ceilometer-detected Sc base height and MBLH from 143 584 corresponding radiosondes indicate that $80 \%$ of the Sc clouds formed directly below the 585 MBL inversion. Accordingly ceilometer-detected $\mathrm{Cu}$ bases heights show broader 586 distribution but mainly occur near the top of the transition layer detected in 74 587 corresponding radiosondes (figures not shown). Fig. 9 shows the averaged 588 thermodynamic structure for $\mathrm{Cu}$ (including multi-layer MBL cloud) and single-layer Sc. 589 A total of 141 radiosonds were analyzed: 104 with Sc near the inversion (Sc top no more 590 than $200 \mathrm{~m}$ below the MBLH) and 37 with $\mathrm{Cu}$ near the transition or multilayer cases $(\mathrm{Cu}$ 591 base more than $200 \mathrm{~m}$ above the transition-layer tops). Application of a layer-by-layer 592 averaging method for the soundings for each cloud category (see section 3.4 for details) 593 requires detectable inversion and transition layers. Analyses of the MAGIC sounding data 594 indicate that both layers are present in the vast majority (94\%) of the soundings. Note that 595 the presence of a transition layer does not necessarily indicate a systematic decoupled 596 MBL (see section 3.5).

597 As seen in Fig. 9, the large vertical gradients in potential temperature and water vapor 598 mixing ratio near $1.5 \mathrm{~km}$ indicate the heights and strengths of the inversion layers, while 599 the smaller changes below $1 \mathrm{~km}$ correspond to transition layers (Fig. 9). The standard 600 deviations of both potential temperature and mixing ratio for both categories are 601 relatively small below the inversion layer, indicating little seasonal variability in profiles 602 of these quantities. Sc cases exhibit lower inversion- and transition-layer heights than $\mathrm{Cu}$ 603 cases, and they have greater potential temperature differences across the inversion 
604 (around $10 \mathrm{~K}$ compared to near $5 \mathrm{~K}$ for $\mathrm{Cu}$ ); the mixing ratio differences across the

605 inversion are nearly the same for both cases, around $6 \mathrm{gkg}^{-1}$. Sc cases exhibit smaller 606 jumps across the transition layer than $\mathrm{Cu}$ for both potential temperature $(<0.5 \mathrm{~K}$ 607 compared to near $1 \mathrm{~K}$ for $\mathrm{Cu})$ and mixing ratio $\left(<1 \mathrm{gkg}^{-1}\right.$ compared to $2 \mathrm{gkg}^{-1}$ for $\left.\mathrm{Cu}\right)$; 608 thus $\mathrm{Cu}$ cases are associated with a much stronger transition layer than $\mathrm{Sc}$, implying a 609 greater chance of a decoupled MBL. However, this stronger transition results in part 610 because the cumuli help maintain the transition layer by mixing dry and warm air from 611 the free troposphere downward.

615 The locations of DE and CB for each leg are shown in Fig. 10. Consistent with previous 616 studies (e.g. Albrecht et al., 1995a; Bretherton and Pincus, 1995; Wyant et al. 1997; 617 Sandu and Stevens, 2011), DE occurred east of CB (when the latter was determined) on 618 all legs. In this section, legs with both DE and CB detected are further examined with the 619 intention to discuss some of the potential controlling factors that are usually neglected in 620 the numerical simulations.

622 4.2.1 Possible controlling factors of MBL systematic decoupling

623 Since DEs and CBs occurred at different locations for individual transects, a 624 normalization of each leg is required in order to develop composites of variables across 
625 these points. Each leg is divided into three regions: east of DE, between DE and CB, and

626 west of $\mathrm{CB}$, and the distance along the transect in each region is normalized (that is, for

627 each leg, the distance from California to any location east of DE is divided by the

628 distance between California and $\mathrm{CB}$, and the CFMBL values for all legs used are

629 averaged over this normalized distance, and similarly for the region between DE and CB,

630 CB and Hawaii).

631 The radiosonde-derived LCL, shown in Fig. 11a as a function of this normalized distance, 632 increases from $450 \mathrm{~m}$ to $750 \mathrm{~m}$ east of $\mathrm{DE}$, decreases slightly to the west of DE, and 633 remains at around $750 \mathrm{~m}$ to the west of CB. Numerical simulations accurately capture the 634 increasing trend of LCL with increasing SST over the well-mixed MBL (Wyant et al. 635 1997; Sandu and Stevens, 2011). The LCL height is more sensitive to the surface 636 moisture than to the temperature. Thus, the increasing LCL height implies a gradual 637 drying of the MBL, mainly due to the increasing entrainment rate with higher SST that is 638 necessary to maintain the energy balance (Bretherton and Wyant, 1997). During MAGIC, 639 it is found that the LCL increase rapidly near DE (Fig. 11a), and the maximum increase 640 in LCL with SST near DEs range from $122 \mathrm{~m} / \mathrm{K}$ to $369 \mathrm{~m} / \mathrm{K}$. The MAGIC observations 641 suggest that this sudden dryness of the MBL is correlated with the entrainment of dryness 642 above the inversion.

643 Fig. $11 \mathrm{~b}$ shows the mean $\Delta \theta_{\mathrm{e}}$ (i.e., averaged over legs) over normalized distance from 644 California to DE. $\Delta \theta_{\mathrm{e}}$ initially increased to near $-2 \mathrm{~K}$ and then decreased to $-6 \mathrm{~K}$ at DE. 645 This decrease is mainly due to the large mean mixing ratio difference across the inversion 646 (Fig. 11c). Plausible explanations for the drier conditions above the inversion are small 647 displacements of the Hadley cell or cold outbreaks behind trailing cold fronts of mid- 
648 latitude cyclones indicated by the increasing sea surface pressure from California to DE 649 (Fig. 10b). The advection due to the large-scale circulation might also contribute. 650 Meanwhile, the increase in both the potential temperature above the inversion (caused by 651 the subsidence of the dry warm air) and that below (due to the increasing SST; Fig. 6g) 652 explains the maintenance of the mean potential temperature difference across the 653 inversion of near $6 \mathrm{~K}$ (Fig. 11d), which contributed less to the decrease $\Delta \theta_{\mathrm{e}}$. The drop in $654 \Delta \theta_{\mathrm{e}}$ east of the DE point increase (Fig. 12) the cloud top entrainment instability and the 655 entrainment rate (Deardorff, 1980) and subsequently less moisture in the MBL. 656 Consistent with the 'deepening-warming mechanism' (Bretherton and Wyant, 1997), our 657 analysis concurs that entrainment plays a crucial role in inducing the MBL decoupling 658 and the MAGIC observations also suggest that the dry warm air above the inversion 659 might be an important trigger.

660 One would expect a dramatic increase of the LHF east of DE due to the dryness of the $661 \mathrm{MBL}$; however, the mean surface latent heat maintained around $120 \mathrm{~W} / \mathrm{m}^{2}$ during that 662 period (Fig. 12a). Therefore, the role of increasing latent heat fluxes in generating the 663 systematic decoupling as suggested in the idealized model (Bretherton and Wyant, 1997) 664 is not captured by the MAGIC observations. The reduction of the mean surface wind 665 speed from California to DE (Fig. 12b) regulate the increase of the LHF, when the ship 666 moved from the edge to the center of the high-pressure system (Fig. 10b). Thus, we 667 conclude that LHF might be important in maintaining the systematic decoupling, but LHF 668 does not play the dominant role in inducing decoupling in MAGIC, which is consistent 669 with the conclusion of Jones et al (2011). 
670 Apart from the systematic decoupling, the weak decoupling $\left(\Delta \mathrm{z}_{\mathrm{i}}>150 \mathrm{~m}\right)$ east of DE are

671 also investigated. Broad peaks of the frequency of occurrence of virga and drizzle were

672 found east of DE, while these frequencies decreased to below $20 \%$ when MBL was

673 decoupled (figures not shown). We found $87 \%$ of which are associated with precipitation.

674 We conclude that precipitation might play a role in inducing decoupling, but this

675 decoupling is usually weak and not continuous, thus precipitation did not show a

676 dominant impact on systematic decoupling. Meanwhile, the diurnal decoupling might

677 also partly explain the weak decoupling east of DE since $73 \%$ of which occurred in the

678 local daytime from 6:00 am to 6:00pm.

679

680 4.2.3 Possible controlling factors of MBL cloud breakup during MAGIC

681 Values of $\mathrm{CF}_{36}$ are typically high along the eastern part of the MAGIC transect (Fig. 10a), 682 especially during the warm season (Fig. 6). The locations where $\mathrm{CF}_{108}$ drop to below $50 \%$ 683 are usually close to $\mathrm{CB}\left(\mathrm{CF}_{108}\right.$ drops to below $\left.15 \%\right)$, indicating the abrupt MBL cloud 684 breakup (Fig. 10a) At the same time, CB is typically located on the west edge of high685 pressure systems (Fig. 10b), implying the role of synoptic interference in the observed 686 MBL cloud breakup.

687 To further investigate this, we analyze the MBL wind profiles near the CB points. A clear 688 synoptic-induced divergence pattern is found. Fig. 13a shows median profiles of zonal $689(\Delta \mathrm{U})$ and latitudinal $(\Delta \mathrm{V})$ wind difference of the composed $\mathrm{U}(\mathrm{V})$ wind east and west of 690 CB in the small and large region. This small region is bounded by two days of radiosonds $691(\sim 1600 \mathrm{~km})$ surrounding $\mathrm{CB}$ while the large region refers to the whole transect. The 
692 profiles shown in Fig. 13a show little sensitivity to the details of the region selected to

693 estimate the wind differences. The well-seperated zonal and latitudinal wind differences

694 around the $\mathrm{CB}$ indicate a systematic divergence in the MBL since the wind to the west of

$695 \mathrm{CB}$ is more easterly $(\Delta \mathrm{U}<0 \mathrm{~m} / \mathrm{s})$, and more southerly $(\Delta \mathrm{V}>0 \mathrm{~m} / \mathrm{s})$ than that to the east. We

696 interpret the east of CB wind pattern as the stable high-pressure systems and the west of

697 CB wind pattern as the signature of approaching mid-latitude cyclone systems. Strong 698 uplifting convergence in the east-approaching cyclones was compensated by the 699 divergence nearby. The drop of the MBLH near CBs provides evidence of the 700 compensating subsidence (Fig. 13b), which is absent in the idealized model with 701 uniformed large scale forcing. Moreover, the averaged mixing ratio difference above the 702 inversion was nearly doubled in the small region (figures not shown). We conclude that 703 the switch of the synoptic environment to the unstable cyclone system can fast break up 704 the MBL cloud and drive vigorous $\mathrm{Cu}$ or deep convective clouds.

\section{SUMMARY AND DISCUSSION}

The MAGIC field campaign, with nearly 200 days of ship-based observations during 20

709 round trips along the $4000 \mathrm{~km}$ transect between California and Hawaii, provided an

710 unparalleled opportunity to acquire data on properties of MBL clouds, precipitation and

711 thermodynamic structure. The measurements obtained during that campaign are used in

712 this manuscript to examine the location and potential controlling factors of systematic

713 MBL decoupling and Sc breakup. 
714 MBL clouds were by far the most frequently observed cloud type during the MAGIC

715 campaign. MBL clouds occurred more often during the warm season (Fig. 5), reflecting

716 the importance of the strong warm-season large-scale Hadley cell (Xu and Cheng, 2013).

717 Among the different MBL cloud types, Sc was the dominant MBL cloud type and

718 occurred more frequently during the warm season than during the cold season (Fig. 8b),

719 while the occurrence of $\mathrm{Cu}$ was less strongly affected by subsidence and exhibited nearly

720 the same behavior for both seasons (Fig. 8b).

722 The formation of Sc just below the inversion requires a shallow MBL with a strong 723 inversion and a weak transition (Fig. 9), providing a greater opportunity to have well-

724 mixed MBL conditions. In contrast, $\mathrm{Cu}$ and multi-layer clouds are usually associated with 725 a much stronger transition, implying a greater chance of decoupling in the MBL.

726 There was a high frequency of occurrence of precipitation throughout the campaign.

727 However, the precipitation from the MBL clouds is weak and often evaporated well 728 before reaching the ocean surface (Fig. 6e). EIS experienced a seasonal variation caused 729 by that of $\theta_{700}$ (Fig. 7c), and generally decreased due to the increasing SST. MBLH 730 generally increased along the transect from California to Hawaii (Fig. 7). East of $135^{\circ} \mathrm{W}$

731 the spatial behavior of MBLH parallels that of the first cloud-top height (Figs. $5 \mathrm{f}$ and $6 \mathrm{~d}$ ),

732 indicating the capped feature of the MBL.

733 The locations of MBL systematic decoupling are determined for individual legs. It is 734 found that a threshold of $\Delta \mathrm{q}>1.5 \mathrm{~g} / \mathrm{kg}$ separates the well-mixed profiles from the 735 systematic decoupled ones (Fig. 5b). Compared to the threshold of $\Delta \mathrm{q}>0.5 \mathrm{gkg}^{-1}$ found in 736 VOCAL-REx (Jones et al., 2011), the MAGIC systematic decoupling showed much 
737 stronger moisture stratification below the inversion. Precipitation and solar radiation

738 correlate well with the weak decoupling points between California and DEs, but neither

739 of them plays a dominant role in the systematic decoupling.

740 A rapid increase of LCL height was found near DEs (Fig. 11s), indicating more rapid 741 drying of the MBL. Correspondingly, the mean cloud top instability showed a sudden

742 increase mainly due to the large mixing ratio difference across the inversion (Fig. 11b,c).

743 These observations imply that the dry warm air from above the inversion is likely of great

744 importance to trigger the systematic decoupling. Consistent with the results in VOCAL-

745 REx (Jones et al., 2011), LHF does not play the dominant role in inducing systematic

746 decoupling in MAGIC. Meanwhile, the mixed layer cloud thickness during MAGIC did

747 not correlate well with the systematic decoupling due to the sudden change of LCL near

748 DEs, further implying that the strong entrainment was driven more by the cloud top

749 instability than by the in-cloud turbulence.

750 DEs nearly always occurred east of CBs (if present) (Fig. 10). MBL clouds tend to

751 breakup abruptly at a location that is typically on the west edge of high-pressure systems

752 (Fig. 10b). A change in synoptic pattern (i.e. different air mass) was often found near CB,

753 which is associated with systematic divergence in the MBL. The divergence, together

754 with downdrafts, compensated for the convergent uplifting in the approaching cyclones.

755 We conclude that the cloud evolution in the idealized model seldom occurs in reality due

756 to synoptic interference.

\section{ACKNOWLEDGMENTS}


760 The MAGIC deployment was supported and undertaken by the U.S. Department of 761 Energy (DOE) Atmospheric Radiation Measurement (ARM) Program Climate Research

762 Facility. The current research was supported by the DOE Atmospheric System Research 763 (ASR) Program (Office of Science, OBER). ERL was supported by the ASR Program 764 under Contract No. DE-AC02-98CH10886. Data used for the analyses were downloaded 765 from the ARM archive (www.arm.gov) except for the MARMET and MARFLUX data, 766 which were provided by Dr. Michael Reynolds of RMR Co. We thank David Painemal of

767 NASA Langley Research Center for providing surface cloud condensation nuclei (CCN) 768 data. We acknowledge the team of scientists and technicians who made this work 769 possible by collecting the data and maintaining the instruments, and especially Horizon

770 Lines and the Captain and crew of the Horizon Spirit for their hospitality. Special thanks 771 go to the cloud research group at McGill University (www.clouds.mcgill.ca) for their 772 helpful comments and constructive criticism. 
Table A1 about here.

\section{Instrument Status Table Leg03A to Leg09B}

787 was installed. During Leg02A and Leg02B, for which instrument status designations are 788 not listed, the radars and other instruments were being set up; some collected data during 789 these legs. During Leg03 most of the instruments were up and collecting data. On

790 Leg09B, the instruments were without power for extended times and were being shut 791 down. The instruments were removed from the ship after Leg09B from January, 2013 792 until May, 2013.

793 Fig. 14 about here.

\section{$794 \quad$ Instrument Status Table Leg10A to Leg18B}

MAGIC instruments were redeployed during Leg10A, and the campaign

797 continued until the end of Leg20B. The technicians did not report instrument status

798 designations for Leg19A and Leg19B, but these were probably similar to those for 799 Leg18B. During Leg20A and Leg20B the instruments were being turned off, so few data 800 were collected during these legs (although sonde launches occurred on Leg20A, 
801 meteorological data were collected until the ship returned to port, and both radars were 802 operating for most of the two legs).

803 Fig 15 about here.

804

805 Table A2 about here.

806 
808 Albrecht, B. A., 1984. "A model study of downstream variations of the thermodynamic 809 structure of the trade winds." Tellus, 36A, 187-202.

810

811 Albrecht, B. A., Randall, D. A., \& Nicholls, S. (1988)."Observations of marine 812 stratocumulus clouds during FIRE." Bulletin of the American Meteorological Society, $813 \quad 69(6), 618-626$.

814

815 Albrecht, B. A., C. S. Bretherton, D. Johnson, W. H. Scubert and A. S. Frisch (1995a). 816 "The Atlantic stratocumulus transition experiment-ASTEX." Bulletin of the American 817 Meteorological Society 76(6): 889-904.

818

819 Albrecht, B. A., Jensen, M. P., \& Syrett, W. J. (1995b). "Marine boundary layer structure 820 and fractional cloudiness." Journal of Geophysical Research: Atmospheres (1984-2012), 821 100(D7), 14209-14222.

822

823 Augstein, E., H. Schmidt and F. Ostapoff (1974). "The vertical structure of the 824 atmospheric planetary boundary layer in undisturbed trade winds over the Atlantic 825 Ocean." Boundary-Layer Meteorology 6(1-2): 129-150.

826

827 Bohren, C. and B. Albrecht (1998). Atmospheric Thermodynamics, Oxford University 828 Press, New York, USA.

829 
830 Boutle, I., R. Beare, S. E. Belcher, A. Brown and R. S. Plant (2010). "The moist 831 boundary layer under a mid-latitude weather system." Boundary-layer meteorology 832

833 Bretherton, C. S., \& Pincus, R. (1995). "Cloudiness and marine boundary layer dynamics 834 in the ASTEX Lagrangian experiments. Part I: Synoptic setting and vertical structure. " 835 Journal of the atmospheric sciences, 52(16), 2707-2723.

836

837 Bretherton, C. S. and M. C. Wyant (1997). "Moisture transport, lower-tropospheric 838 stability, and decoupling of cloud-topped boundary layers." Journal of the Atmospheric 839 Sciences 54(1): 148-167.

840

841 Cadeddu, M. (2012). Microwave Radiometer-3 Channel (MWR3C) Handbook, DOE 842 Office of Science Atmospheric Radiation Measurement (ARM) Program (United States). 843

844 Cheng, A. and K.-M. Xu (2013). "Evaluating Low Cloud Simulation from an Upgraded 845 Multiscale Modeling Framework Model. Part III: Tropical and Subtropical Cloud 846 Transitions over the Northern Pacific." Journal of Climate 26: 5761-5781.

847

848 Deardorff, J. (1980). "Cloud top entrainment instability." Journal of the Atmospheric 849 Sciences 37(1): 131-147.

850

851 Fairall, C. W., E. F. Bradley, D. P. Rogers, J. B. Edson, and G. S. Young (1996). "Bulk 852 parameterization of air-sea fluxes for Tropical Ocean-Global Atmosphere Couple-Ocean 
853 Atmosphere Response Experiment." Journal of Geophysical Research 101 (C2):37478543764.

855

856 Heck, P. W., B. J. Byars, D. F. Young, P. Minnis, and E. F. Harrison 1990. "A 857 climatology of satellite derived cloud properties over marine stratocumulus regions. " 858 Preprints, Conf. on Cloud Physics, San Francisco, CA, Amer. Meteor. Soc., J1-J7.

859

860 Hildebrand, P. H. and R. Sekhon (1974). "Objective determination of the noise level in 861 Doppler spectra." Journal of Applied Meteorology 13(7): 808-811.

863 Jones, C. R., Bretherton, C. S., \& Leon, D. (2011). "Coupled vs. decoupled boundary

864 layers in VOCALS-REx." Atmospheric Chemistry and Physics, 11(14), 7143-7153.

865

866 Karlsson, J., Svensson, G., Cardoso, S., Teixeira, J., \& Paradise, S. (2010). "Subtropical

867 cloud-regime transitions: Boundary layer depth and cloud-top height evolution in models 868 and observations." Journal of Applied Meteorology and Climatology, 49(9), 1845-1858.

870 King, M. D., Y. J. Kaufman, W. Menzel and D. Tanre (1992). "Remote sensing of cloud, 871 aerosol, and water vapor properties from the Moderate Resolution Imaging Spectrometer 872 (MODIS)." IEEE Transactions on Geoscience and Remote Sensing 30(1): 2-27.

873

874 Klein, S. A. and D. L. Hartmann (1993). "The seasonal cycle of low stratiform clouds." 875 Journal of Climate 6(8): 1587-1606. 
877 Kollias, P., E. Clothiaux, M. Miller, B. Albrecht, G. Stephens and T. Ackerman (2007).

878 "Millimeter-wavelength radars: New frontier in atmospheric cloud and precipitation

879 research." Bulletin of the American Meteorological Society 88(10): 1608-1624.

880

881 Krueger, S. K., McLean, G. T., \& Fu, Q. (1995). "Numerical simulation of the stratus-to882 cumulus transition in the subtropical marine boundary layer. Part I: Boundary-layer 883 structure. Journal of the atmospheric sciences. " 52(16), 2839-2850.

884

885 Larson, K., D. L. Hartmann and S. A. Klein (1999). "The role of clouds, water vapor, 886 circulation, and boundary layer structure in the sensitivity of the tropical climate." Journal 887 of Climate 12(8): 2359-2374.

888

889 Lewis, E. R., W. J. Wiscombe, B. A. Albrecht, G. L. Bland, C. N. Flagg, S. A. Klein, P. 890 Kollias, G. Mace, R. Reynolds and S. Schwartz (2012). "MAGIC: Marine ARM GPCI 891 Investigation of Clouds.".

892

893 Liljegren, J. (1994). Two-channel microwave radiometer for observations of total column 894 precipitable water vapor and cloud liquid water path. Fifth Symposium on Global Change 895 Studies.

896

897 Lilly, D. K. (1968). "Models of cloud-topped mixed layers under a strong inversion." 898 Quarterly Journal of the Royal Meteorological Society 94(401): 292-309. 
900 Lohmann, U. and J. Feichter (2005). "Global indirect aerosol effects: a review." 901 Atmospheric Chemistry and Physics 5(3): 715-737.

902

903 Ma, C.-C., C. R. Mechoso, A. W. Robertson and A. Arakawa (1996). "Peruvian stratus 904 clouds and the tropical Pacific circulation: A coupled ocean-atmosphere GCM study." 905 Journal of Climate 9(7): 1635-1645.

906

907 Matrosov, S. Y. (2007). "Potential for attenuation-based estimations of rainfall rate from 908 CloudSat." Geophysical Research Letters 34(5): L05817.

909

910 Miller, M. A., M. P. Jensen and E. E. Clothiaux (1998). "Diurnal cloud and 911 thermodynamic variations in the stratocumulus transition regime: A case study using in 912 situ and remote sensors." Journal of the Atmospheric Sciences 55(13): 2294-2310.

913

914 Morris, V. (2006). "Microwave radiometer (MWR) handbook." ARM-TR016.

915

916 Neiburger, M. (1961). Studies of the structure of the atmosphere over the eastern Pacific 917 ocean in summer, University of California Press.

918

919 Norris, J. R. and C. B. Leovy (1994). "Interannual variability in stratiform cloudiness and 920 sea surface temperature." Journal of Climate 7(12): 1915-1925. 
922 Philander, S., D. Gu, G. Lambert, T. Li, D. Halpern, N. Lau and R. Pacanowski (1996).

923 "Why the ITCZ is mostly north of the equator." Journal of Climate 9(12): 2958-2972.

924

925 Rémillard, J., P. Kollias, E. Luke and R. Wood (2012). "Marine Boundary Layer Cloud

926 Observations in the Azores." Journal of Climate 25(21): 7381-7398.

927

928 Riehl, H., T. Yeh, J. Malkus and N. La Seur (1951). "The north-east trade of the Pacific

929 Ocean." Quarterly Journal of the Royal Meteorological Society 77(334): 598-626.

930

931 Rossow, W. B. and R. A. Schiffer (1999). "Advances in understanding clouds from

932 ISCCP." Bulletin of the American Meteorological Society 80(11): 2261-2287.

933

934 Sandu, I. and B. Stevens (2011). "On the factors modulating the stratocumulus to 935 cumulus transitions." Journal of the Atmospheric Sciences 68(9): 1865-1881.

936

937 Stephens, G. L. (2005). "Cloud feedbacks in the climate system: A critical review." 938 Journal of Climate 18(2): 237-273.

939

940 Teixeira, J., S. Cardoso, M. Bonazzola, J. Cole, A. DelGenio, C. DeMott, C. Franklin, C.

941 Hannay, C. Jakob, Y. Hiao, J. Karlsson, H. Kitagawa, M. Köhler, A. Kuwano-Hoshida, C.

942 LeDrain, A. Lock, M. H. Miller, P. Marquet, J. Martins, C. R. Mechoso, E. V. Meijgaard,

943 I. Meinke, A. M. A. Miranda, D. Mironov, R. Neggers, H. L. Pan, D. A. Randall, P. J.

944 Rasch, B. Rockel, W. B. Rossow, B. Ritter, A. P. Siebesma, P. Soares, F. J. Turk, P. A. 
945 Vaillancourt, A. Von Engeln, and M. Zhao (2011). "Tropical and subtropical cloud 946 transitions in weather and climate prediction models: The GCSS/WGNE Pacific Cross947 Section Intercomparison (GPCI)." Journal of Climate 24(20): 5223-5256.

948

949 Tiedtke, M., W. A. Hackley and J. Slingo, 1988. "Tropical forecasting at ecmwf: The 950 influence of physical parameterization on the mean structure of forecasts and analyses." 951 Q. J. R. Meteorol. Soc., 114, 639-664.

952

953 Wang, S., B. A. Albrecht, and P. Minnis, 1993. "A regional simulation of marine 954 boundary layer clouds." J. Atmos. Sci., 50, 4022-4043.

955

956 Wyant, M. C., C. S. Bretherton, H. A. Rand, and D. E. Stevens, 1997. "Numerical 957 simulations and a conceptual model of the subtropical marine stratocumulus to trade 958 cumulus transition." J. Atmos. Sci., 54, 168-192.

959

960 Widener, K., N. Bharadwaj and K. Johnson (2012). "Ka-Band ARM Zenith Radar 961 (KAZR) Instrument Handbook." DOE Office of Science Atmospheric Radiation 962 Measurement (ARM) Program (United States).

963

964 Wood, R. (2012). "Stratocumulus clouds." Monthly Weather Review 140(8): 2373-2423. 965 
966 Wood, R. and C. S. Bretherton (2004). "Boundary layer depth, entrainment, and 967 decoupling in the cloud-capped subtropical and tropical marine boundary layer." Journal 968 of Climate 17(18): 3576-3588.

969

970 Wood, R. and C. S. Bretherton (2006). "On the relationship between stratiform low cloud 971 cover and lower-tropospheric stability." Journal of Climate 19(24): 6425-6432.

972

973 Wood, R., C. Mechoso, C. Bretherton, R. Weller, B. Huebert, F. Straneo, B. Albrecht, H. 974 Coe, G. Allen and G. Vaughan (2011). "The vamos ocean-cloud-atmosphere-land study 975 regional experiment (VOCALS-REx): Goals, platforms, and field operations." 976 Atmospheric Chemistry and Physics 11(2): 627-654.

977

978 Xu, K.-M. and A. Cheng (2013). "Evaluating Low Cloud Simulation from an Upgraded 979 Multiscale Modeling Framework Model. Part II: Seasonal Variations over the Eastern 980 Pacific." Journal of Climate 26: 5717-5740.

981

982 Yin, B. and B. A. Albrecht (2000). "Spatial variability of atmospheric boundary layer 983 structure over the eastern equatorial Pacific." Journal of Climate 13(9): 1574-1592.

984

985

986

987 
991 Table 1. Cloud types and characteristics used to differentiate them in the identification

992 algorithm (Ind: indeterminate).

\begin{tabular}{|c|c|c|c|c|c|c|c|}
\hline & \multicolumn{6}{|c|}{ Type } \\
\hline & & \multirow{2}{*}{$\begin{array}{l}\text { High- } \\
\text { level }\end{array}$} & \multirow{2}{*}{ Mid-level } & \multicolumn{3}{|c|}{ MBL } & \multirow{2}{*}{$\begin{array}{l}\mathrm{Cu} \\
\text { congestus } \\
\text { and deep } \\
\text { convective }\end{array}$} \\
\hline & & & & $\mathrm{Sc}$ & $\mathrm{Cu}$ & Ind & \\
\hline \multicolumn{2}{|c|}{ Minimum cloud base } & $\geq 6 \mathrm{~km}$ & $3-6 \mathrm{~km}$ & $<3 \mathrm{~km}^{*}$ & $<3 \mathrm{~km}^{*}$ & $<3 \mathrm{~km}^{*}$ & $<3 \mathrm{~km}$ \\
\hline \multicolumn{2}{|c|}{ Maximum cloud top } & - & - & $<3 \mathrm{~km}$ & $<3 \mathrm{~km}$ & $<3 \mathrm{~km}$ & $\geq 3 \mathrm{~km}$ \\
\hline \multicolumn{2}{|c|}{ Duration } & - & - & $\geq 20 \mathrm{~min}$ & $<20 \mathrm{~min}$ & $\geq 20 \mathrm{~min}$ & - \\
\hline \multirow{3}{*}{$\begin{array}{l}\text { Cloud top } \\
\text { height } \\
\text { standard } \\
\text { deviation }\end{array}$} & $\begin{array}{l}{[20 \mathrm{~min},} \\
2 \mathrm{~h}]\end{array}$ & - & - & $<100 \mathrm{~m}$ & - & $\geq 100 \mathrm{~m}$ & - \\
\hline & $\begin{array}{l}(2 \mathrm{~h}, \\
10 \mathrm{~h}]\end{array}$ & - & - & $<160 \mathrm{~m}$ & - & $\geq 160 \mathrm{~m}$ & - \\
\hline & $>10 \mathrm{~h}$ & - & - & $<200 \mathrm{~m}$ & - & $\geq 200 \mathrm{~m}$ & - \\
\hline
\end{tabular}

993

994

$995 *$ Minimum cloud base for MBL clouds are either below $3 \mathrm{~km}$ or undetermined

996

997

998

999

1000

1001

1002 
1003 Table 2. List of liquid precipitation types and their main characteristics used to 1004 differentiate them.

1005

1006

\begin{tabular}{|l|l|l|l|l|l|}
\hline \multirow{2}{*}{} & \multicolumn{5}{|c|}{ Type } \\
\cline { 2 - 6 } & Virga & Drizzle & Warm Rain & Cold Rain & Convective Rain \\
\hline Echo base & $>$ First gate & $=$ First gate & $=$ First gate & $=$ First gate & $=$ First gate \\
\hline $\begin{array}{l}\text { Base } \\
\text { reflectivity }\end{array}$ & - & $<0 \mathrm{dBZ}$ & $>0 \mathrm{dBZ}$ & $>0 \mathrm{dBZ}$ & $>0 \mathrm{dBZ} \&$ \\
\hline $\begin{array}{l}\text { Surface } \\
\text { Rain }\end{array}$ & No & No & Yes & Yes & $\begin{array}{l}>\text { First Top } \\
\text { reflectivity }\end{array}$ \\
\hline $\begin{array}{l}\text { First cloud } \\
\text { top height }\end{array}$ & $\begin{array}{l}\text { Below } 0{ }^{\circ} \mathrm{C} \\
\text { isotherm }\end{array}$ & $\begin{array}{l}\text { Below } 0{ }^{\circ} \mathrm{C} \\
\text { isotherm }\end{array}$ & $\begin{array}{l}\text { Below } 0{ }^{\circ} \mathrm{C} \\
\text { isotherm }\end{array}$ & $\begin{array}{l}\text { Above } 0{ }^{\circ} \mathrm{C} \\
\text { isotherm }\end{array}$ & - \\
\hline $\begin{array}{l}\text { Echo below } \\
\text { cloud base }\end{array}$ & $\begin{array}{l}\text { Yes }(50 \mathrm{~m} \\
\text { lower })\end{array}$ & $\begin{array}{l}\text { Yes }(50 \mathrm{~m} \\
\text { lower })\end{array}$ & Possible & Possible & Possible \\
\hline
\end{tabular}

1007

1008

1009

1010

1011

1012

1013

1014 
1015 Table A1. Departure and arrival times of each leg.

1016 All times are UTC.

1017

\begin{tabular}{|l|l|l|l|l|}
\hline & \multicolumn{2}{|c|}{ A } & \multicolumn{2}{c|}{ B } \\
\hline & Depart LA & Arrive HI & \multicolumn{1}{c|}{ Depart HI } & Arrive LA \\
\hline Leg00 & $2012-02-11,13: 30$ & $2012-02-16,09: 00$ & $2012-02-17,09: 00$ & $2012-02-23,15: 00$ \\
\hline Leg01 & & & $2012-09-14,23: 20$ & $2012-09-20,13: 40$ \\
\hline Leg02 & $2012-09-22,12: 15$ & $2012-09-27,05: 50$ & $2012-09-28,09: 50$ & $2012-10-04,14: 20$ \\
\hline Leg03 & $2012-10-06,11: 30$ & $2012-10-11,06: 30$ & $2012-10-12,08: 00$ & $2012-10-18,13: 30$ \\
\hline Leg04 & $2012-10-20,11: 25$ & $2012-10-25,06: 15$ & $2012-10-26,06: 40$ & $2012-11-01,13: 20$ \\
\hline Leg05 & $2012-11-03,17: 50$ & $2012-11-08,15: 00$ & $2012-11-09,17: 30$ & $2012-11-15,15: 00$ \\
\hline Leg06 & $2012-11-17,12: 20$ & $2012-11-22,07: 30$ & $2012-11-24,10: 15$ & $2012-11-30,01: 20$ \\
\hline Leg07 & $2012-12-01,13: 30$ & $2012-12-06,09: 00$ & $2012-12-07,08: 20$ & $2012-12-13,14: 45$ \\
\hline Leg08 & $2012-12-15,13: 00$ & $2012-12-20,08: 30$ & $2012-12-22,08: 15$ & $2012-12-28,00: 00$ \\
\hline Leg09 & $2012-12-29,12: 30$ & $2013-01-03,07: 00$ & $2013-01-05,04: 50$ & $2013-01-13,03: 35$ \\
& & & & SEE NOTE 1 \\
\hline Leg10 & $2013-05-11,11: 20$ & $2013-05-16,06: 20$ & $2013-05-17,16: 30$ & $2013-05-23,14: 00$ \\
\hline Leg11 & $2013-05-25,11: 25$ & $2013-05-30,06: 30$ & $2013-05-31,11: 15$ & $2013-06-06,13: 30$ \\
\hline Leg12 & $2013-06-08,11: 25$ & $2013-06-13,06: 35$ & $2013-06-14,16: 35$ & $2013-06-20,13: 35$ \\
\hline Leg13 & $2013-06-22,11: 30$ & $2013-06-27,07: 45$ & $2013-06-28,17: 30$ & $2013-07-03,23: 10$ \\
\hline Leg14 & $2013-07-07,17: 35$ & $2013-07-12,06: 50$ & $2013-07-13,11: 45$ & $2013-07-18,23: 15$ \\
\hline Leg15 & $2013-07-20,12: 00$ & $2013-07-25,05: 45$ & $2013-07-26,13: 10$ & $2013-08-01,13: 30$ \\
\hline Leg16 & $2013-08-03,13: 30$ & $2013-08-08,05: 40$ & $2013-08-09,10: 15$ & $2013-08-15,14: 30$ \\
\hline Leg17 & $2013-08-17,18: 30$ & $2013-08-22,10: 15$ & $2013-08-23,17: 15$ & $2013-08-29,13: 20$ \\
\hline Leg18 & $2013-08-31,11: 45$ & $2013-09-05,06: 35$ & $2013-09-06,12: 00$ & $2013-09-12,13: 40$ \\
\hline Leg19 & $2013-09-14,12: 25$ & $2013-09-19,06: 20$ & $2013-09-20,11: 20$ & $2103-09-26,13: 55$ \\
\hline Leg20 & $2013-09-28,11: 35$ & $2013-10-03,06: 35$ & $2013-10-04,10: 05$ & $2013-10-10,13: 35$ \\
& & & & \\
\hline
\end{tabular}

1018

1019 NOTE 1: During Leg09B the Spirit had its engines off for approximately 14 hours on

1020 2013-01-06 and 2013-01-07; thus the trajectory will look abnormal for this time as the

1021 ship was drifting. Soon thereafter the entire ship, including the AMF2, was without

1022 power for approximately one hour, and some instruments might not have resumed

1023 operation before the end of the leg. Data acquisition stopped 2013-01-11 for some

1024 instruments and on 2013-01-12 for all instruments. After the Spirit arrived in port in Los 
1025 Angeles after Leg09B, the AMF2 was removed from the ship (it was completely off the 1026 Spirit by 2013-01-13, 21:00 UTC) and placed in storage, where it remained until 1027 reinstallation on 2013-05-09.

1028 NOTE 2: MAGIC instrumentation was being turned off and packed during Leg20 and all 1029 MAGIC instrumentation was removed from the Spirit on 2013-10-10 by 22:00.

1030

1031

1032

1033

1034

1035

1036

1037

1038

1039

1040

1041 
1043 characteristics. The $1^{\text {st }}$ cloud base, top and thickness in the table refer to those of the

$1044 \quad$ lowest clouds.

\begin{tabular}{|c|c|c|c|c|c|c|c|c|}
\hline \multicolumn{2}{|c|}{$\begin{array}{l}\text { Distance from } \\
\text { California Coast }\end{array}$} & $100 \mathrm{~km}$ & $500 \mathrm{~km}$ & $1000 \mathrm{~km}$ & $2000 \mathrm{~km}$ & $3000 \mathrm{~km}$ & $3600 \mathrm{~km}$ & $4000 \mathrm{~km}$ \\
\hline \multirow{3}{*}{$\begin{array}{l}\text { Cloud } \\
\text { fractional } \\
\text { coverage }\end{array}$} & Total & $0.62 \pm 0.44$ & $0.69 \pm 0.43$ & $0.74 \pm 0.41$ & $0.62 \pm 0.38$ & $0.30 \pm 0.38$ & $0.33 \pm 0.28$ & $0.22 \pm 0.28$ \\
\hline & Cold & $0.49 \pm 0.47$ & $0.54 \pm 0.46$ & $0.71 \pm 0.44$ & $0.54 \pm 0.44$ & $0.21 \pm 0.27$ & $0.29 \pm 0.26$ & $0.17 \pm 0.27$ \\
\hline & Warm & $0.76 \pm 0.37$ & $0.88 \pm 0.31$ & $0.79 \pm 0.40$ & $0.71 \pm 0.29$ & $0.40 \pm 0.48$ & $0.38 \pm 0.31$ & $0.27 \pm 0.29$ \\
\hline \multirow{3}{*}{$\begin{array}{l}1^{\text {st }} \text { Cloud } \\
\text { base }[\mathrm{km}]\end{array}$} & Total & $0.51 \pm 0.42$ & $0.62 \pm 0.34$ & $0.98 \pm 0.38$ & $1.14 \pm 0.28$ & $1.05 \pm 0.40$ & $1.20 \pm 0.43$ & $1.11 \pm 0.46$ \\
\hline & Cold & $0.85 \pm 0.49$ & $0.69 \pm 0.47$ & $1.04 \pm 0.52$ & $1.10 \pm 0.20$ & $1.09 \pm 0.49$ & $1.09 \pm 0.46$ & $1.17 \pm 0.53$ \\
\hline & Warm & $0.27 \pm 0.08$ & $0.55 \pm 0.15$ & $0.92 \pm 0.17$ & $1.18 \pm 0.36$ & $1.00 \pm 0.26$ & $1.32 \pm 0.39$ & $1.04 \pm 0.37$ \\
\hline \multirow{3}{*}{$\begin{array}{l}1^{\text {st }} \text { Cloud } \\
\text { top }[\mathrm{km}]\end{array}$} & Total & $0.89 \pm 0.75$ & $0.91 \pm 0.42$ & $1.19 \pm 0.28$ & $1.39 \pm 0.28$ & $1.20 \pm 0.47$ & $1.43 \pm 0.47$ & $1.24 \pm 0.35$ \\
\hline & Cold & $1.36 \pm 0.90$ & $1.02 \pm 0.56$ & $1.17 \pm 0.35$ & $1.39 \pm 0.24$ & $1.19 \pm 0.57$ & $1.31 \pm 0.52$ & $1.15 \pm 0.31$ \\
\hline & Warm & $0.48 \pm 0.13$ & $0.80 \pm 0.16$ & $1.20 \pm 0.19$ & $1.39 \pm 0.33$ & $1.23 \pm 0.34$ & $1.57 \pm 0.39$ & $1.33 \pm 0.39$ \\
\hline \multirow{3}{*}{$\begin{array}{l}1^{\text {st }} \text { Cloud } \\
\text { thickness } \\
{[\mathrm{km}]}\end{array}$} & Total & $0.35 \pm 0.39$ & $0.27 \pm 0.22$ & $0.23 \pm 0.15$ & $0.23 \pm 0.16$ & $0.19 \pm 0.15$ & $0.17 \pm 0.13$ & $0.24 \pm 0.18$ \\
\hline & Cold & $0.60 \pm 0.51$ & $0.30 \pm 0.30$ & $0.18 \pm 0.11$ & $0.25 \pm 0.16$ & $0.18 \pm 0.16$ & $0.15 \pm 0.15$ & $0.26 \pm 0.19$ \\
\hline & Warm & $0.18 \pm 0.14$ & $0.24 \pm 0.11$ & $0.27 \pm 0.17$ & $0.21 \pm 0.16$ & $0.21 \pm 0.15$ & $0.21 \pm 0.08$ & $0.21 \pm 0.17$ \\
\hline
\end{tabular}

1045

1046 Means and standard deviations of the cloud macroscopic properties at different

1047 locations along the MAGIC transect (100, 500, 1000, 2000, 3000, 3600 and $4000 \mathrm{~km}$

1048 from the coast of California) for all applicable MAGIC legs (Leg3-8, Leg11, Leg14-

1049 17). Data during each leg are binned to a uniform great circle route with $36-\mathrm{km}$

$1050 \quad$ resolution.

1051

1052 
1054

1055

1056

1057

1058

1059

1060

1061

1062

1063

1064

1065

1066

1067

1068

1069

1070

1071

1072

1073
1. (a) Horizon Spirit showing location of the bridge region where the AMF2 was located, and (b) Tracks of MAGIC legs between California and Hawaii (red lines) and great circle route (blue line).

2. KAZR reflectivity observations for Leg04A (top panel) and Leg04B (bottom panel) with the first ceilometer cloud base shown as black dots. The Spirit departed from California on Oct. 21 (2012) and arrived in Hawaii on Oct. 25, then left on Oct. 26 and returned to California on Nov. 1. Graphs are shown with Los Angeles to the right and Honolulu to the left. The ceilometer data for 00:00 to $\sim 21: 16$ UTC on Oct. 22, 2012 are not available.

3. (a) Cloud classifications for Leg04 with the first ceilometer cloud base shown as black dots. The corresponding KAZR reflectivities can be seen in Fig 2. (b) KAZR reflectivities with the first and second ceilometer cloud base shown as black and red dots respectively for a short time segment on Oct. 21, 2012 during Leg04A. (c) MBL cloud classifications with the first and second ceilometer cloud base shown as black and red dots for the same time period as that shown in Fig. 3b during Leg04A. (d) KAZR reflectivities with the first ceilometer cloud base shown as black dots for a short time period on Oct. 28, 2012 during Leg04B. The pink, light blue and purple backgrounds indicate the occurrence of virga, MBL drizzle, and heavy MBL drizzle, respectively; the yellow background indicates no precipitation during that time period. 
4. Profiles of temperature $(\mathrm{T})$, potential temperature $(\theta)$, and mixing ratio $(\mathrm{r})$

1076

1077

1078

1079

1080

1081

1082

1083

1084

1085

1086

1087

1088

1089

1090

1091

1092

1093

1094

1095

1096

1097 from soundings. Green and blue dashed lines show the inversion tops and bases, while black and red dashed lines show the transition tops and bases. (a) Sounding launched at 18:08 UTC, October 26, 2012, with broken $\mathrm{Cu}$ overhead. (b) Sounding launched at 12:00 UTC, October 29, 2012, with overcast Sc overhead.

5. (a) The scatter plot of radiosonde-derived $\Delta \mathrm{q}$ for all the legs and maximum $\Delta \mathrm{zb}$ within four degrees longitude surrounding each radiosonde. The solid black line is the least square fit with slope $276 \mathrm{~m} \mathrm{~kg}$ g-1 and intercept $200 \mathrm{~m}$. The dashed black line represents the thermodynamic argument derived in Jone et al 2011. The red dots indicate outliers outside 1.5 standard deviation of the least-square fit. (b) Radiosonde-derived $\Delta \mathrm{q}$ for all the legs along the normalized path from California to DE to Hawaii.

6. Frequencies of occurrence along the MAGIC transect of (a) the four main cloud types, (b) MBL clouds and observed MBL-cloud liquid precipitation, and (c) MBL clouds and (d) observed MBL-cloud liquid precipitation during the warm and cold season during the warm season (Leg11, Leg14-Leg17: May 25 -June 6, 2013, July 7-Aug. 29, 2013) and during the cold season (Leg03-Leg08: Oct. 6-Dec. 27, 2012). Total and seasonal mean along the MAGIC transect of (e) first cloud base heights, (f) first cloud top heights, and 
(g) SSST. The black line shows the total mean, the blue and the red line shows the mean for cold and warm season respectively. The gray shaded region indicates one standard deviation of the mean. Frequencies of occurrence along the MAGIC transect of (h) liquid precipitation types.

7. Total and seasonal mean of (a) MBLH, and (b) EIS along the MAGIC transect. The gray shaded region indicates one standard deviation of total. The black line shows the total mean, the blue line shows the mean of the cold season, and the red line the mean for the warm season, and (c) Leg-mean values of EIS, SSST, potential temperature at $700 \mathrm{hPa}$, and potential temperature at the surface.

8. Frequencies of occurrence of cloud types (a) over the entire deployment and (b) during the cold season and warm season. water vapor mixing ratio composed over the cases with single stratocumulus at the inversion level (blue dotted line), and single cumulus at the transition level together with multiple MBL clouds (red solid line), both of which must contain a transition layer. legs. The black triangle and the black dots indicate the cloud breakup points 
(CB) and the starting points of the MBL systematic decoupling (DE). The red crosses in (a) indicate the location when $\mathrm{CF}_{108}$ drops to below $50 \%$ before $\mathrm{CB}$. White spaces in (a) denote times when $\mathrm{CF}_{36}$ was less than $10 \%$, and those in (b) denote missing data.

11. Total mean of (a) the radiosonde-derived LCL along the normalized path from California to Hawaii, (b) the equivalent potential temperature difference across the inversion, (c) the mixing ratio difference at the inversion, and (d) the potential temperature difference at the inversion along the normalized path from California to DE. Gray shaded region indicates interquartile range. The boxplot in (b) and (c) indicates the location of the maximum and minimum value near DE, the difference between the two is significant at $95 \%$ confident level.

12. The total mean (a) surface latent heat flux, and (b) surface wind speed along the normalized path from California to Hawaii. Gray shaded region indicates interquartile range. $\mathrm{CB}$ and that west of $\mathrm{CB}$ in the small region (solid black line) and in the large region (dashed black line); same for $\mathrm{V}$ wind difference in the small region (solid red line) and in the large region (dashed red line). Shaded area indicates 

Hawaii. 

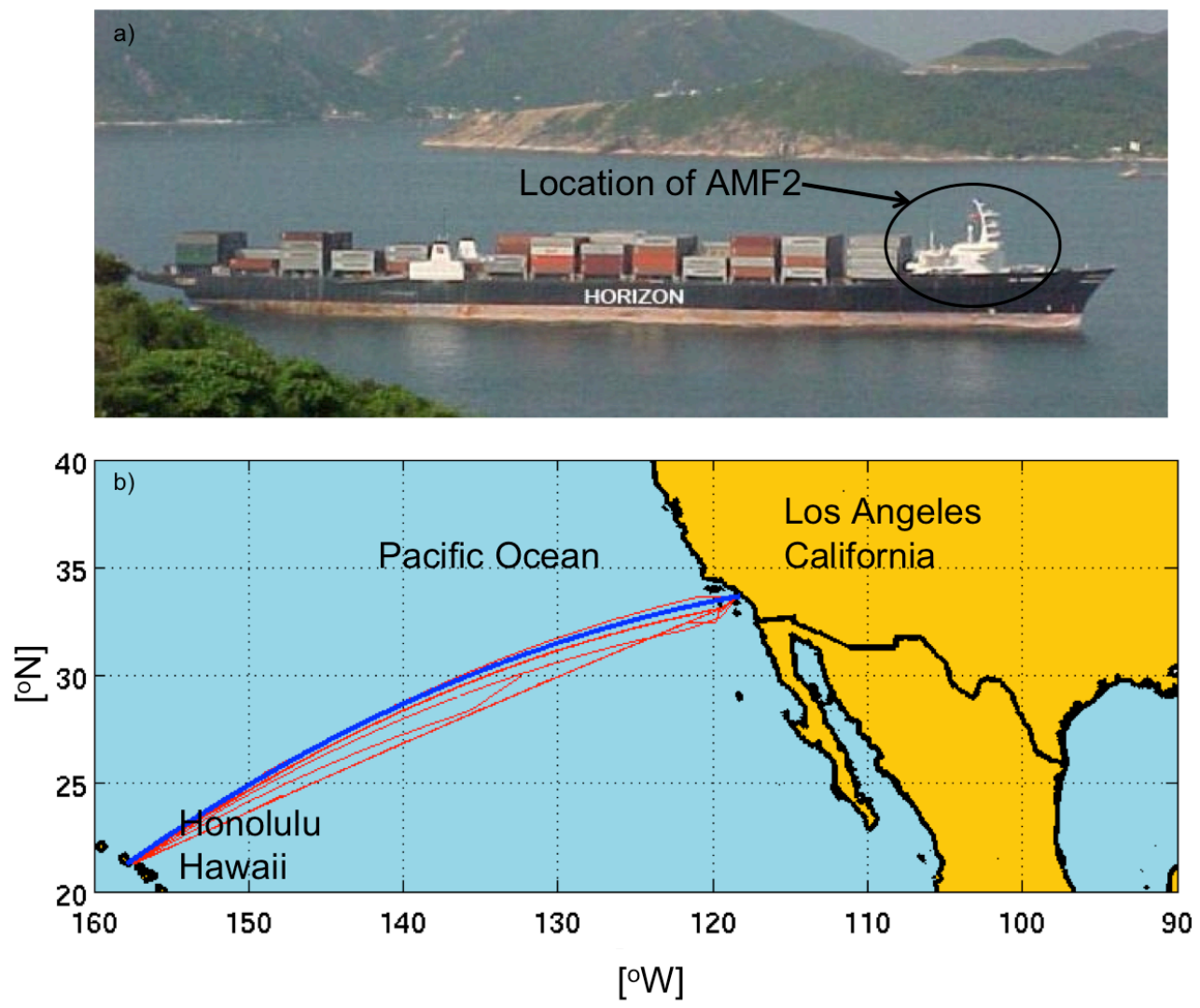

Fig. 1. (a) Horizon Spirit showing location of the bridge region where the AMF2 was located, and (b) Tracks of MAGIC legs between California and Hawaii (red lines) and great circle route (blue line). 

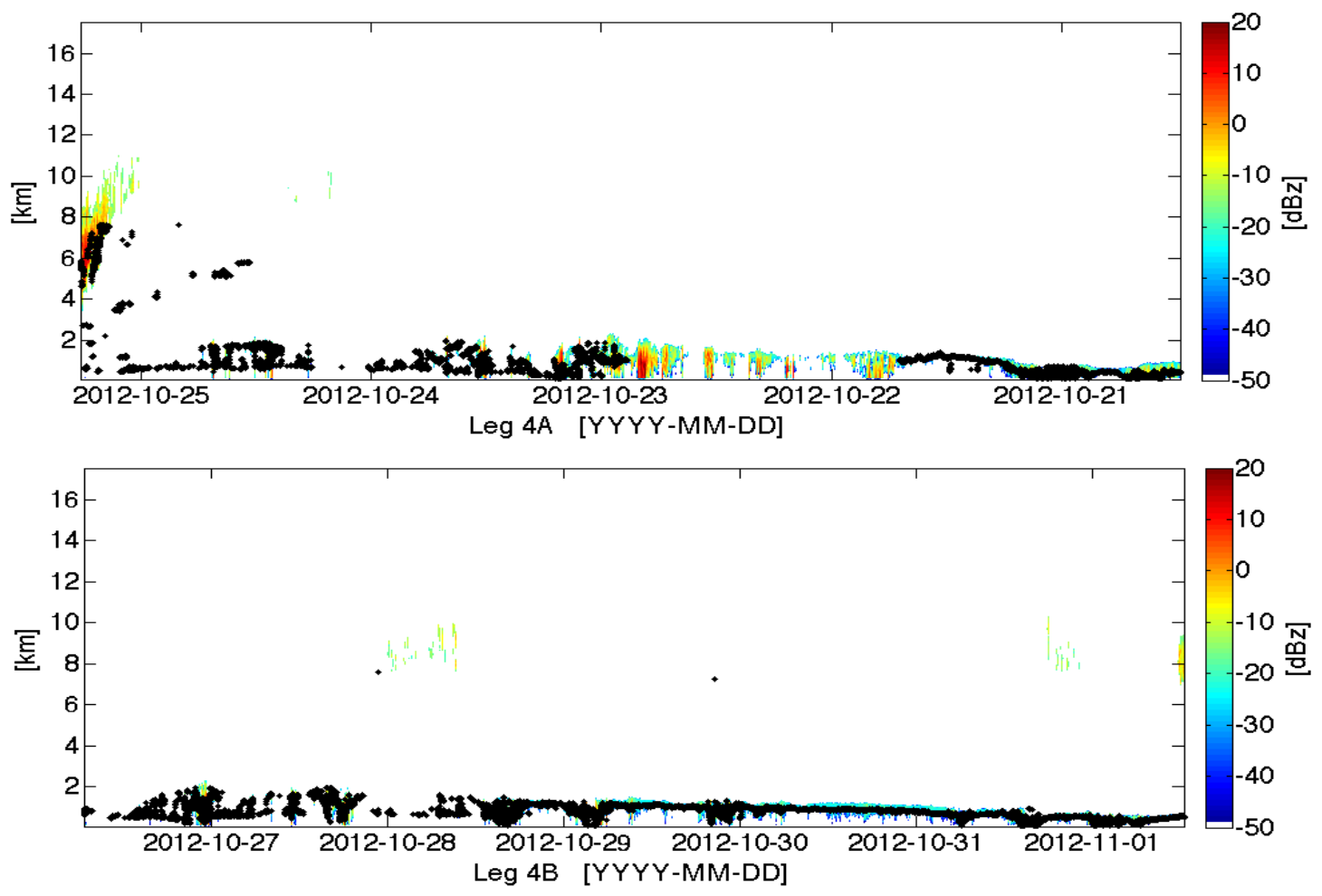

1173 Fig. 2. KAZR reflectivity observations for Leg04A (top panel) and Leg04B (bottom

1174 panel) with the first ceilometer cloud base shown as black dots. The Spirit departed from

1175 California on Oct. 21 (2012) and arrived in Hawaii on Oct. 25, then left on Oct. 26 and

1176 returned to California on Nov. 1. Graphs are shown with Los Angeles to the right and

1177 Honolulu to the left. The ceilometer data for 00:00 to $\sim 21: 16$ UTC on Oct. 22, 2012 are

1178 not available.

1179

1180

1181 

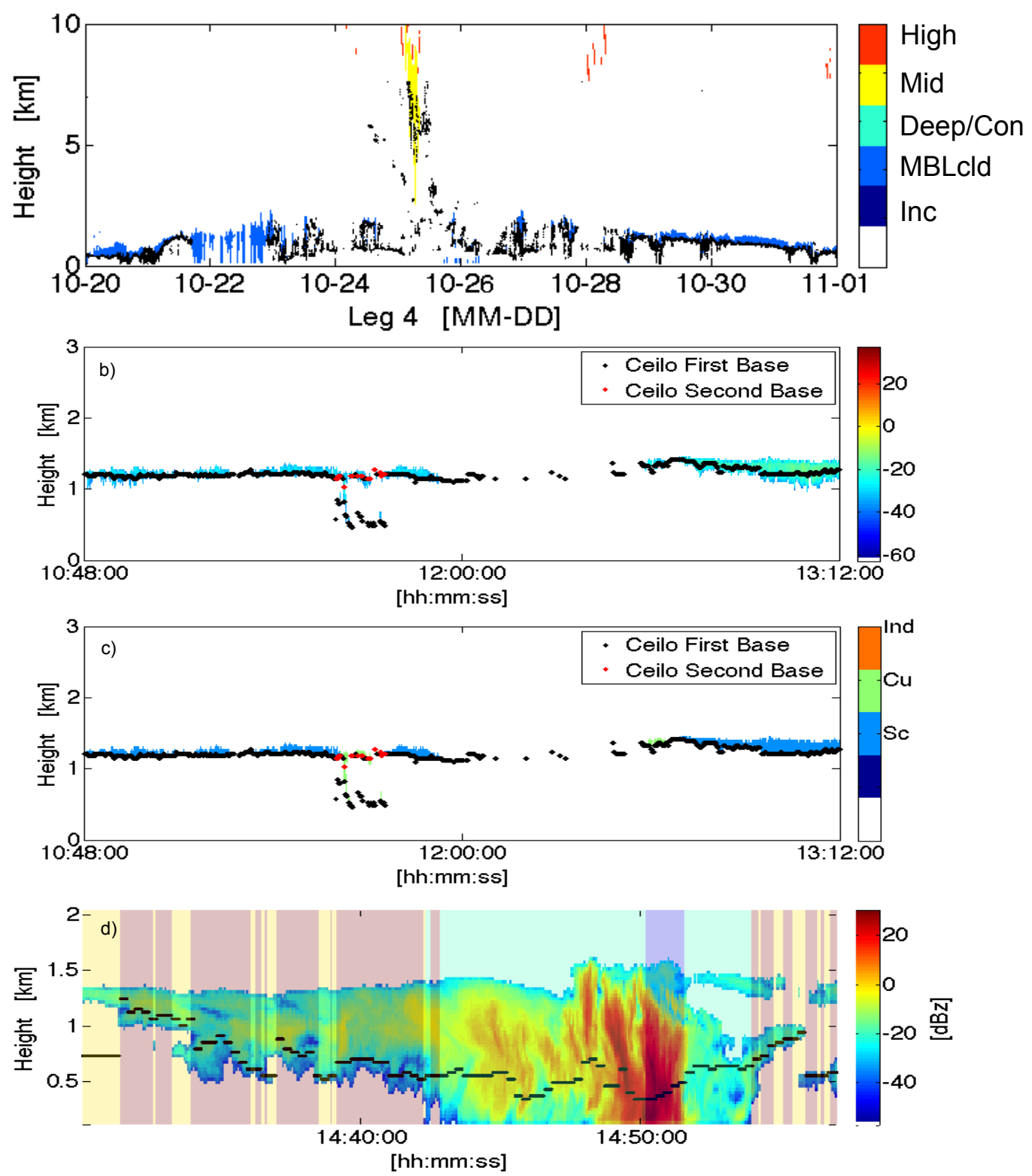

1183 Fig. 3. (a) Cloud classifications for Leg04 with the first ceilometer cloud base shown as

1184 black dots. The corresponding KAZR reflectivities can be seen in Fig 2. (b) KAZR

1185 reflectivities with the first and second ceilometer cloud base shown as black and red dots

1186 respectively for a short time segment on Oct. 21, 2012 during Leg04A. (c) MBL cloud

1187 classifications with the first and second ceilometer cloud base shown as black and red

1188 dots for the same time period as that shown in Fig. 3b during Leg04A. (d) KAZR 
1189 reflectivities with the first ceilometer cloud base shown as black dots for a short time 1190 period on Oct. 28, 2012 during Leg04B. The pink, light blue and purple backgrounds 1191 indicate the occurrence of virga, MBL drizzle, and heavy MBL drizzle, respectively; the 1192 yellow background indicates no precipitation during that time period.

1193 

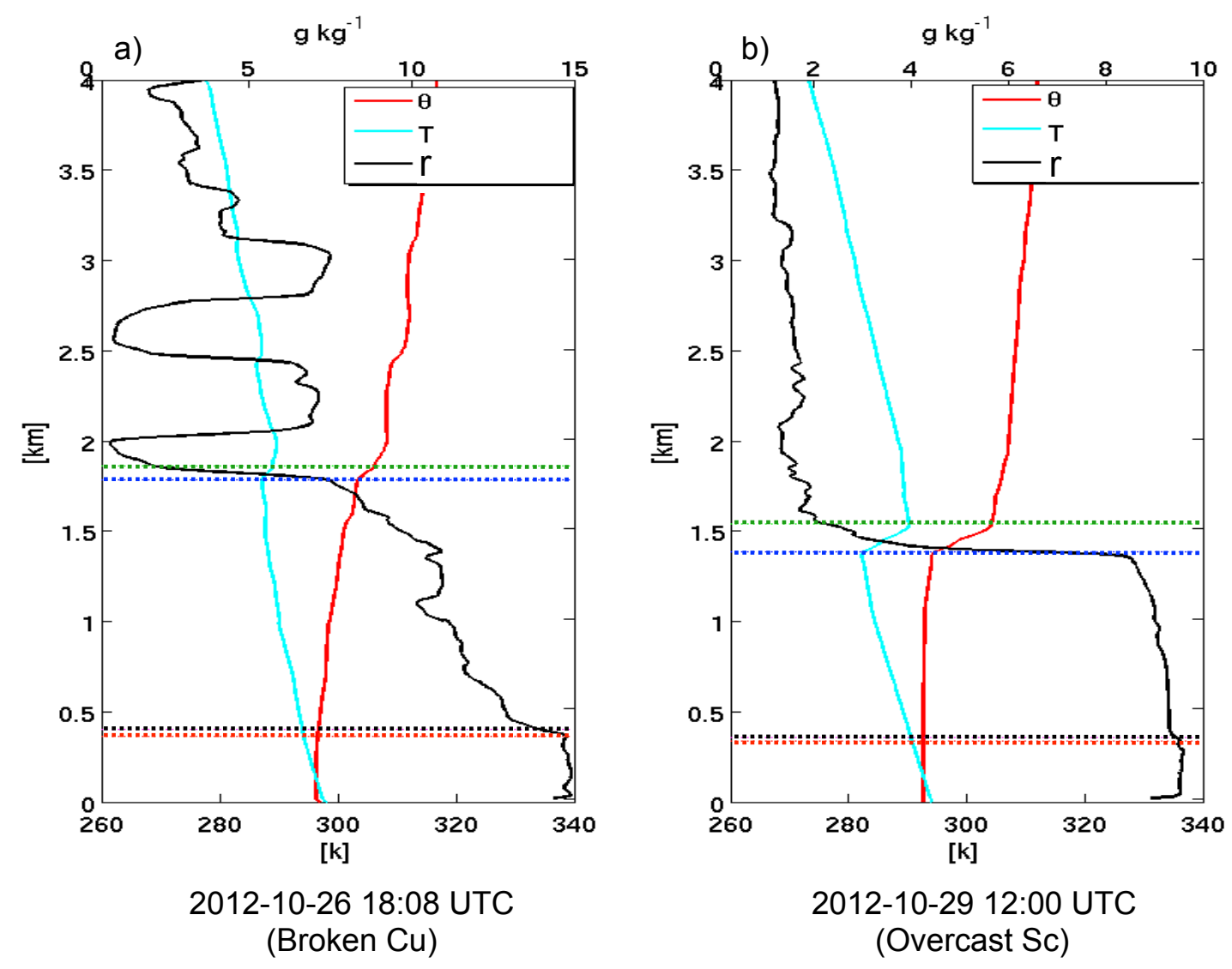

1195

1196 Fig. 4. Profiles of temperature (T), potential temperature ( $\theta)$, and mixing ratio (r) from 1197 soundings. Green and blue dashed lines show the inversion tops and bases, while black 1198 and red dashed lines show the transition tops and bases. (a) Sounding launched at 18:08 1199 UTC, October 26, 2012, with broken Cu overhead. (b) Sounding launched at 12:00 UTC, 1200 October 29, 2012, with overcast Sc overhead. 

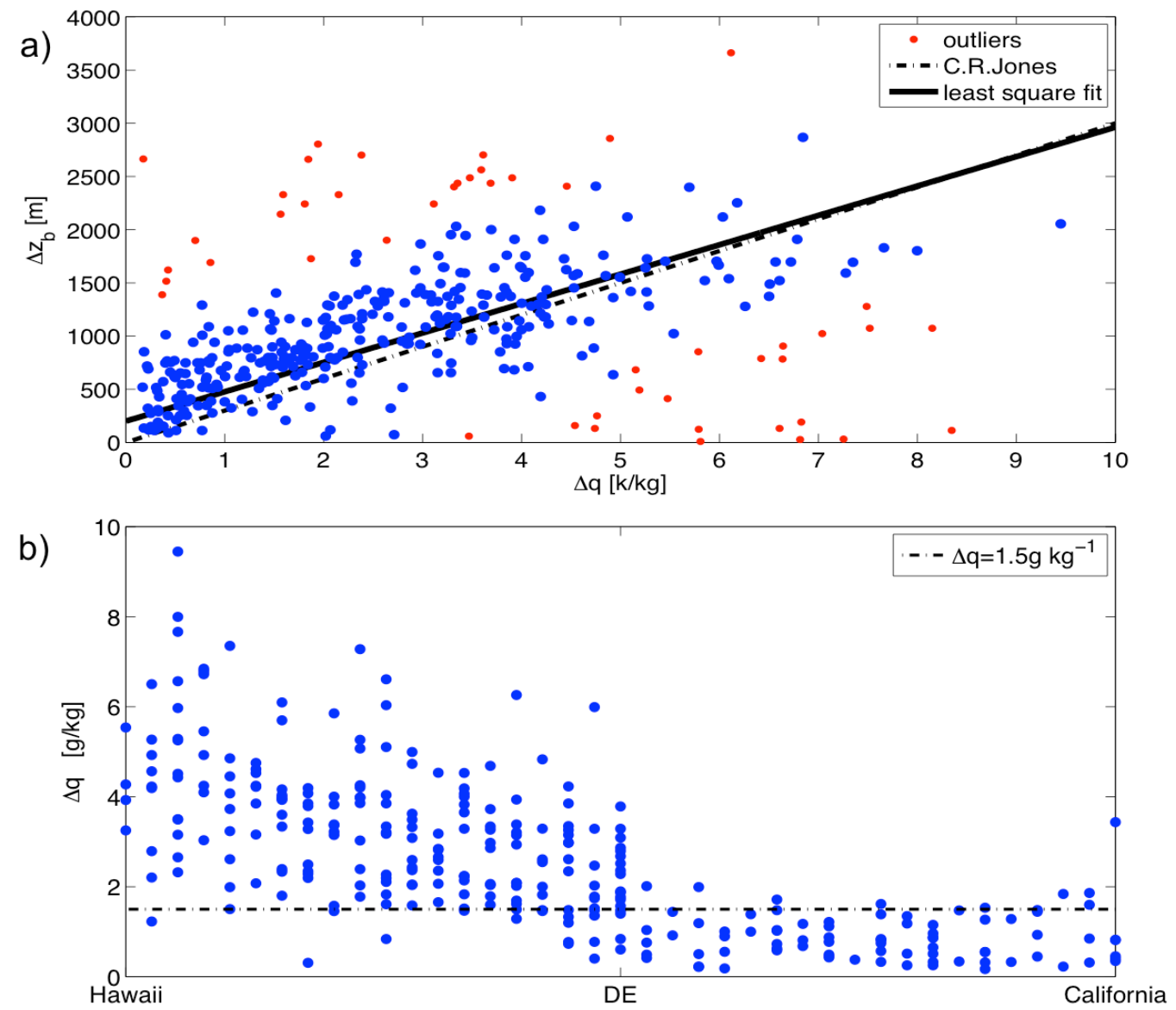

1202 Fig. 5(a) The scatter plot of radiosonde-derived $\Delta \mathrm{q}$ for all the legs and maximum $\Delta \mathrm{zb}$ 1203 within four degrees longitude surrounding each radiosonde. The solid black line is the 1204 least square fit with slope $276 \mathrm{~m} \mathrm{~kg}$ g-1 and intercept $200 \mathrm{~m}$. The dashed black line 1205 represents the thermodynamic argument derived in Jone et al 2011. The red dots indicate 1206 outliers outside 1.5 standard deviation of the least-square fit. (b) Radiosonde-derived $\Delta \mathrm{q}$ 1207 for all the legs along the normalized path from California to DE to Hawaii. 

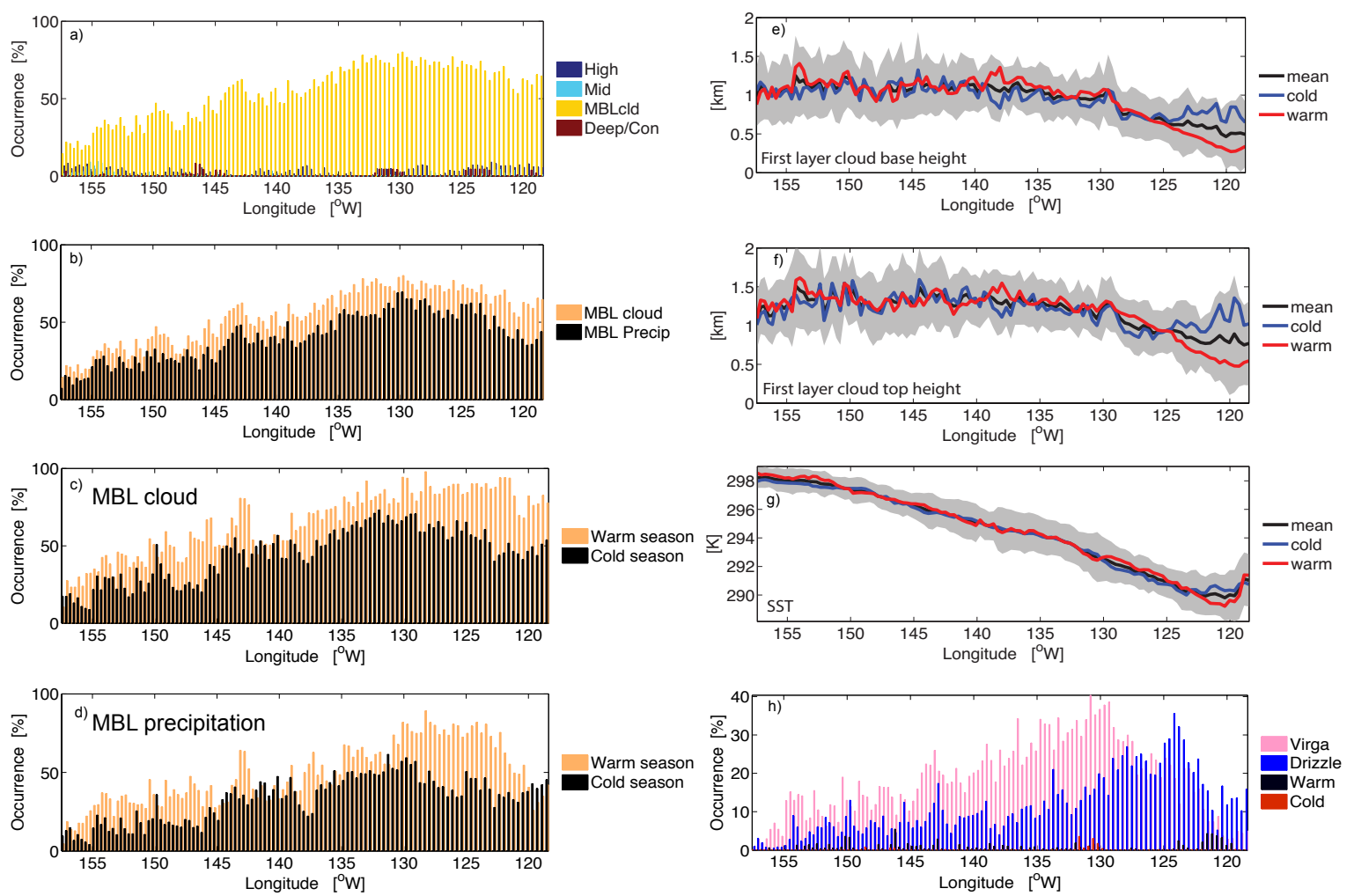

1210 Fig. 6. Frequencies of occurrence along the MAGIC transect of (a) the four main cloud

1211 types, (b) MBL clouds and observed MBL-cloud liquid precipitation, and (c) MBL

1212 clouds and (d) observed MBL-cloud liquid precipitation during the warm and cold season

1213 during the warm season (Leg11, Leg14-Leg17: May 25 -June 6, 2013, July 7-Aug. 29,

1214 2013) and during the cold season (Leg03-Leg08: Oct. 6-Dec. 27, 2012). Total and

1215 seasonal mean along the MAGIC transect of (e) first cloud base heights, (f) first cloud top

1216 heights, and (g) SSST. The black line shows the total mean, the blue and the red line

1217 shows the mean for cold and warm season respectively. The gray shaded region indicates

1218 one standard deviation of the mean. Frequencies of occurrence along the MAGIC transect

1219 of (h) liquid precipitation types.

1220

1221 

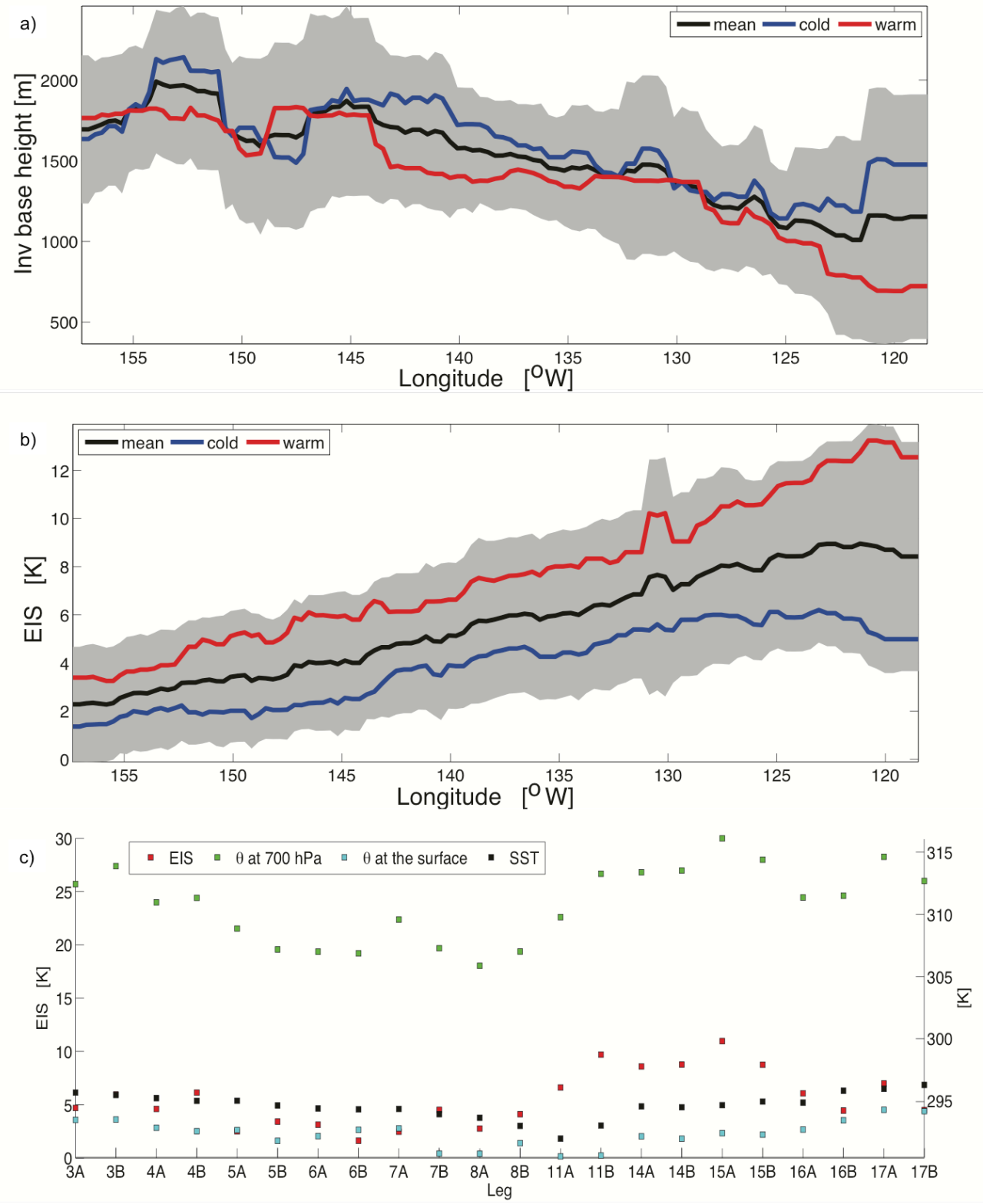

1224 Fig. 7. Total and seasonal mean of (a) MBLH, and (b) EIS along the MAGIC transect.

1225 The gray shaded region indicates one standard deviation of total. The black line shows

1226 the total mean, the blue line shows the mean of the cold season, and the red line the mean

1227 for the warm season, and (c) Leg-mean values of EIS, SSST, potential temperature at 700

$1228 \mathrm{hPa}$, and potential temperature at the surface. 

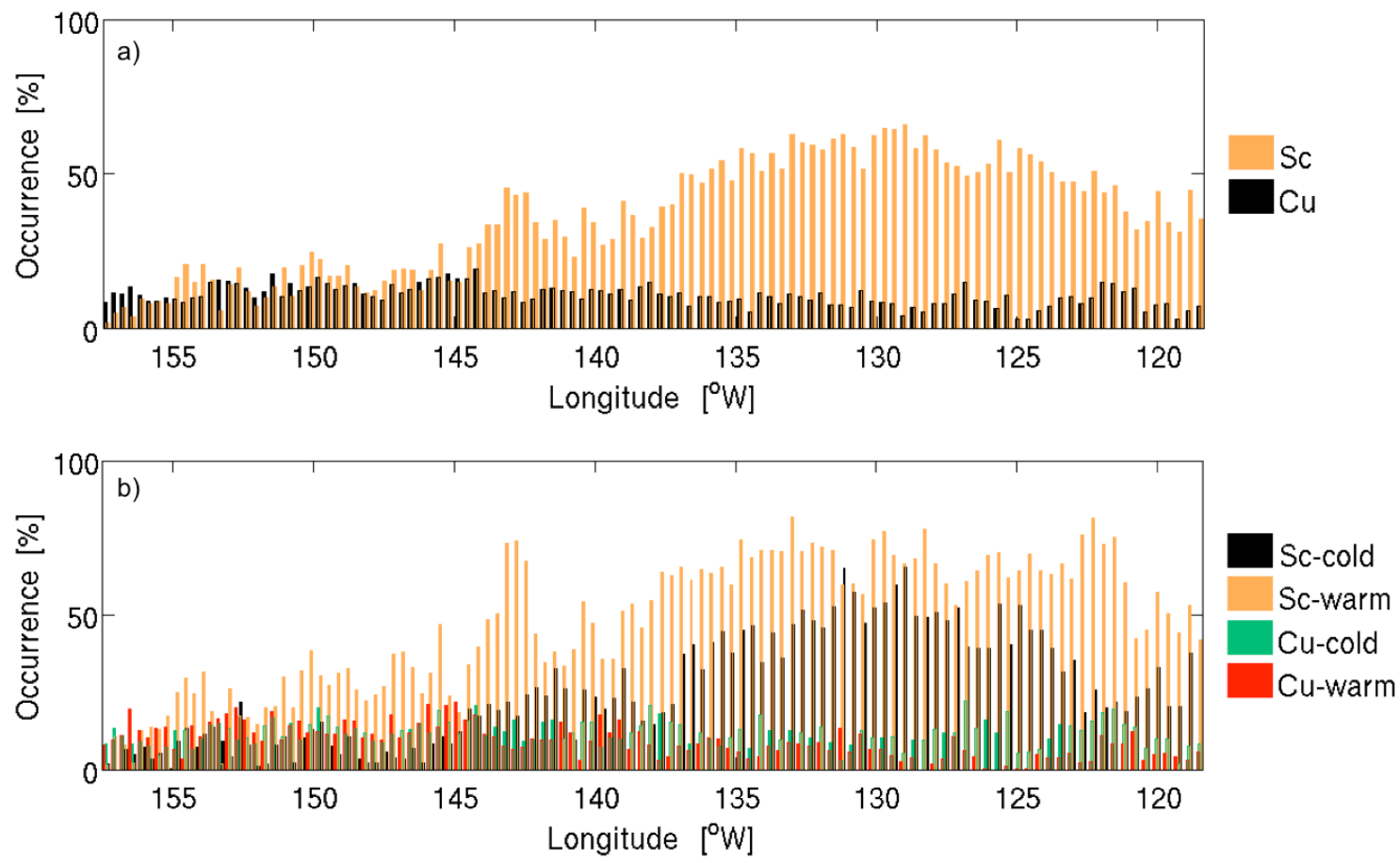

1230 Fig. 8. Frequencies of occurrence of cloud types (a) over the entire deployment and (b)

1231 during the cold season and warm season. 
a) Std Composite potential temperature profile for MAGIC

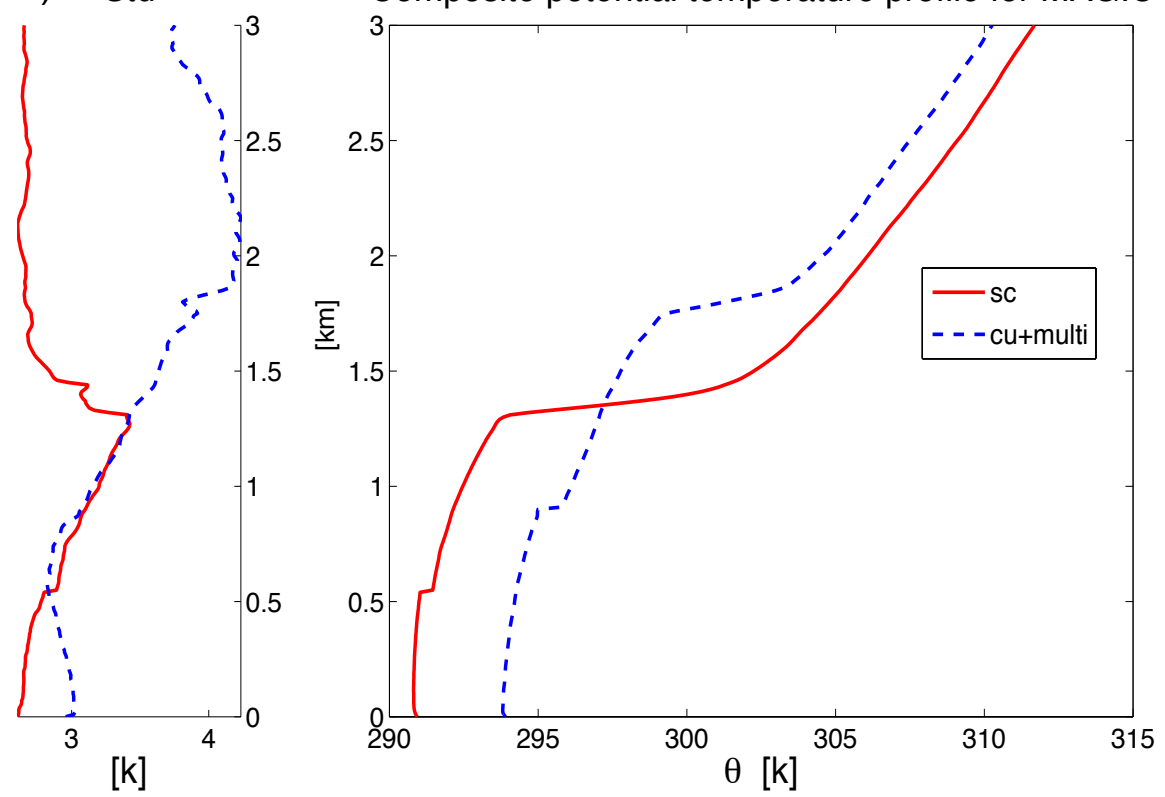

b) Std Composite r profile for MAGIC

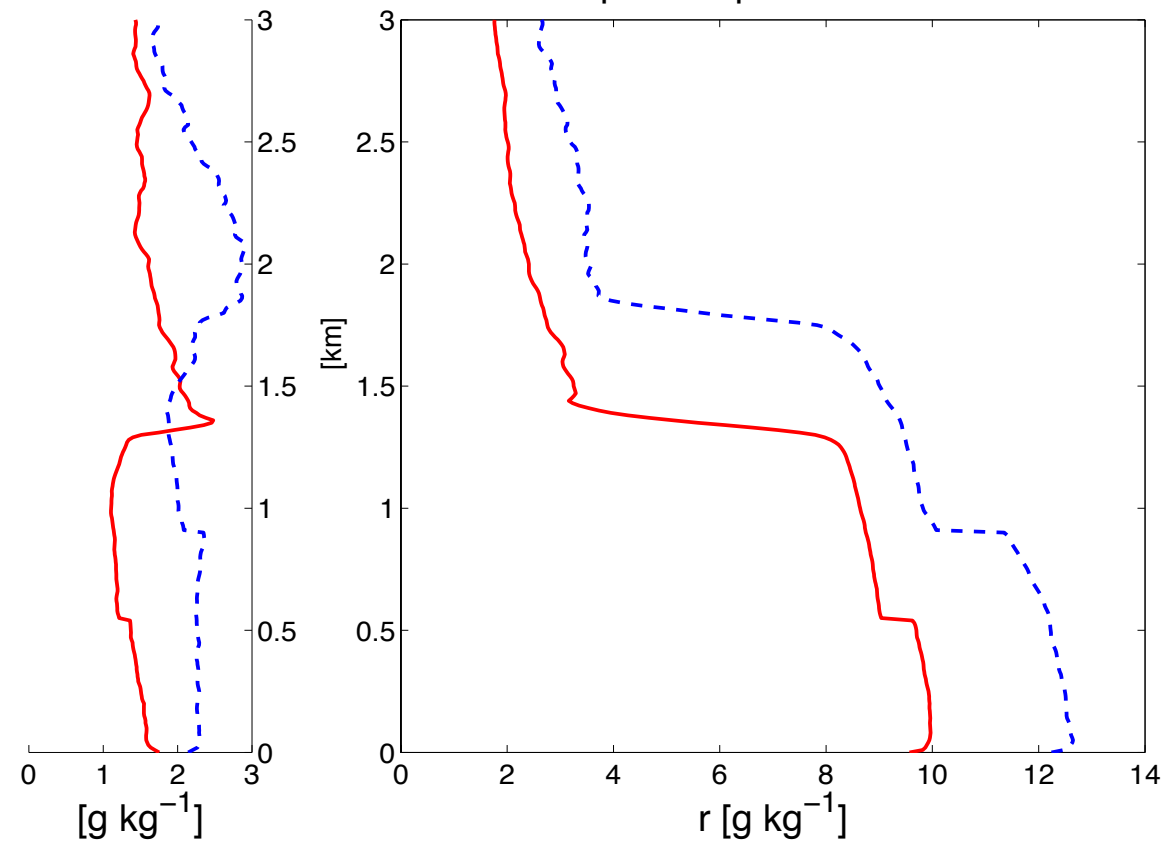

1233 Fig. 9. Profiles of means and standard deviations of (a) potential temperature and (b)

1234 water vapor mixing ratio composed over the cases with single stratocumulus at the 1235 inversion level (blue dotted line), and single cumulus at the transition level together with 1236 multiple MBL clouds (red solid line), both of which must contain a transition layer. 

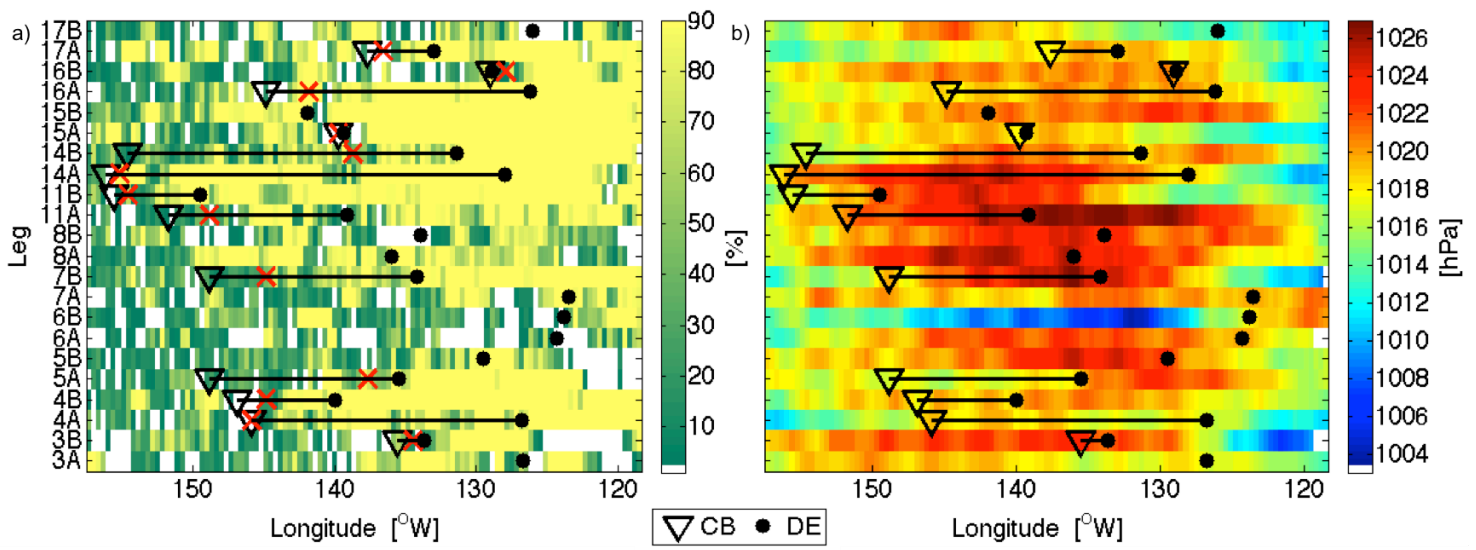

1238 Fig. 10(a) $\mathrm{CF}_{36}$, (b) the sea surface pressure along the MAGIC transect for individual legs.

1239 The black triangle and the black dots indicate the cloud breakup points (CB) and the

1240 starting points of the MBL systematic decoupling (DE). The red crosses in (a) indicate

1241 the location when $\mathrm{CF}_{108}$ drops to below $50 \%$ before $\mathrm{CB}$. White spaces in (a) denote times

1242 when $\mathrm{CF}_{36}$ was less than $10 \%$, and those in (b) denote missing data.

1243

1244

1245

1246

1247 

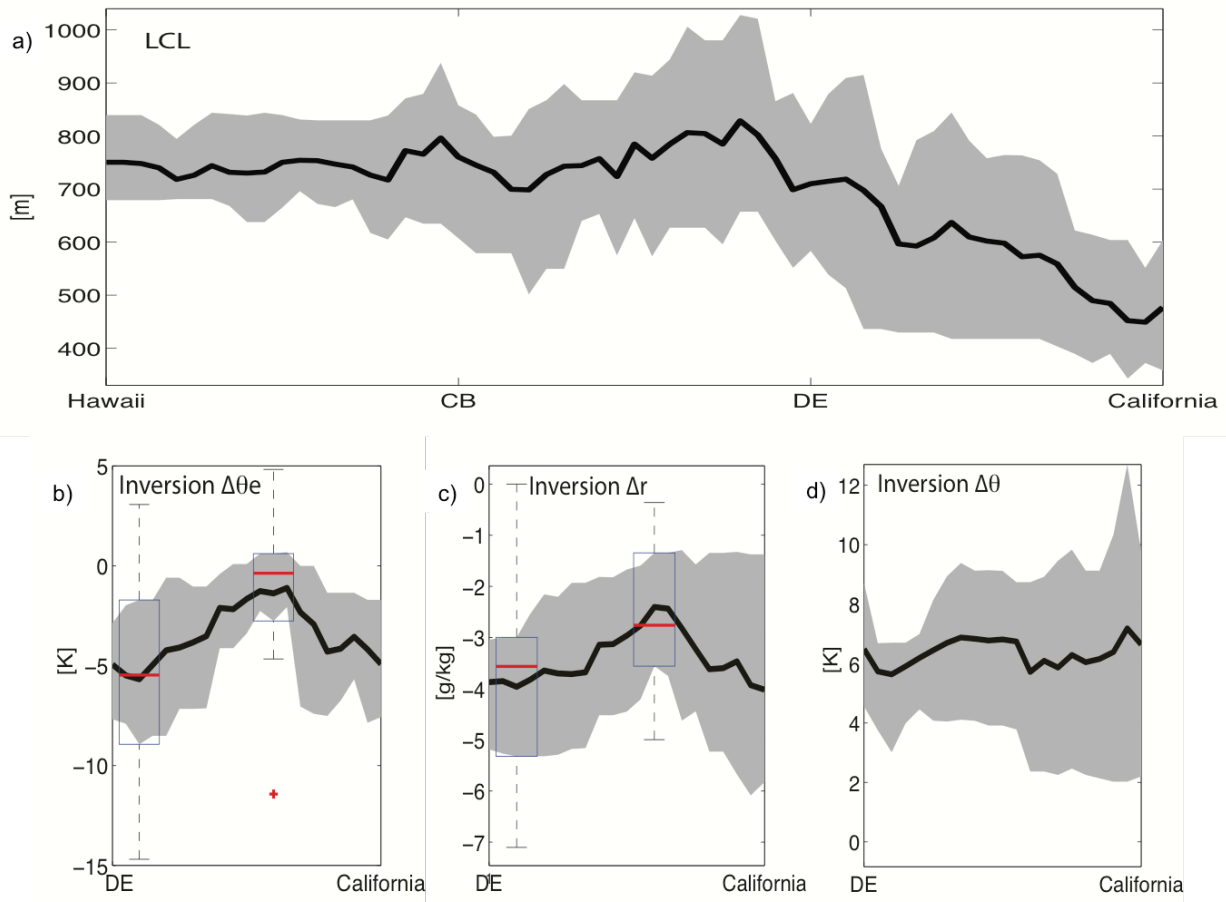

1249 Fig. 11. Total mean of (a) the radiosonde-derived LCL along the normalized path from 1250 California to Hawaii, (b) the equivalent potential temperature difference across the 1251 inversion, (c) the mixing ratio difference at the inversion, and (d) the potential 1252 temperature difference at the inversion along the normalized path from California to DE.

1253 Gray shaded region indicates interquartile range. The boxplot in (b) and (c) indicates the 1254 location of the maximum and minimum value near $\mathrm{DE}$, the difference between the two is 1255 significant at $95 \%$ confident level. 

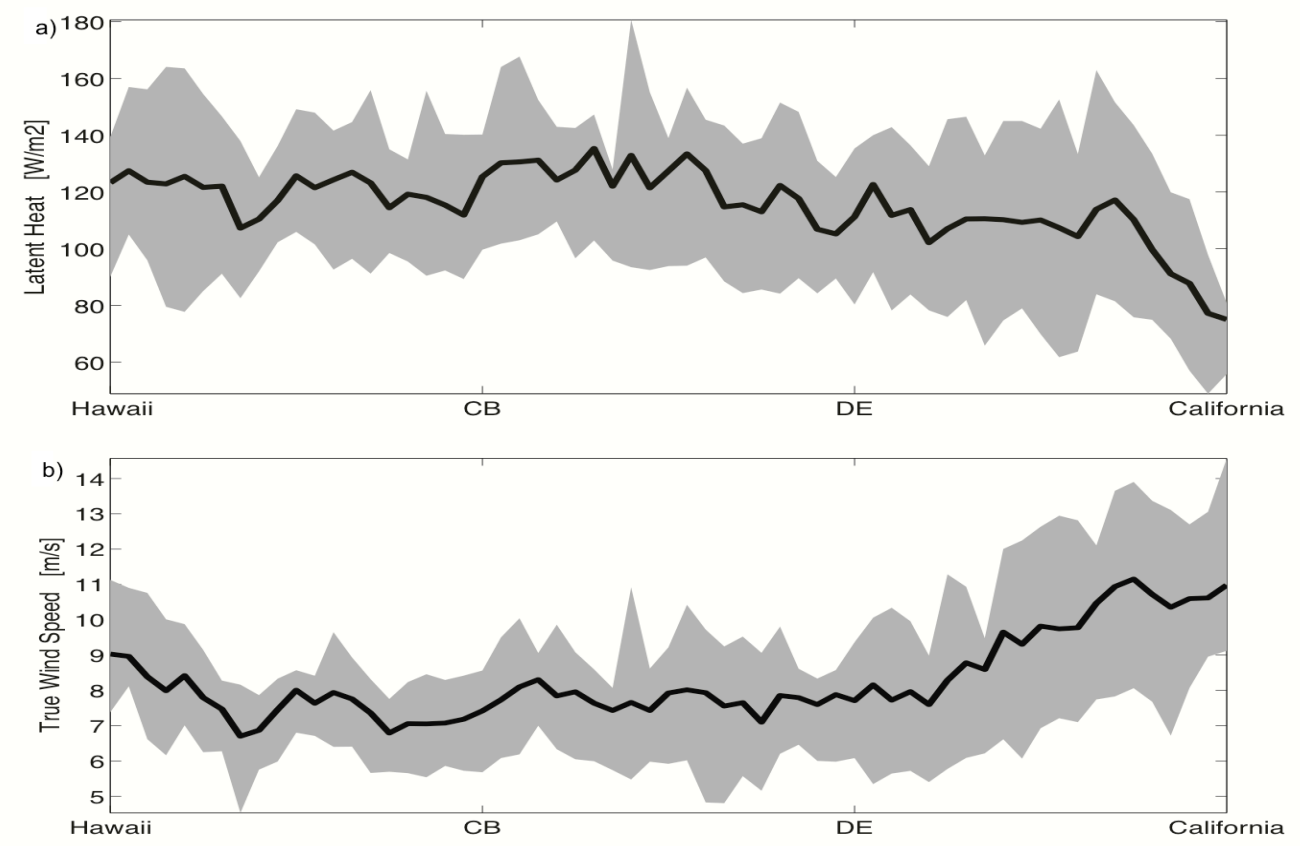

1263 Fig. 12 The total mean (a) surface latent heat flux, and (b) surface wind speed along the

1264 normalized path from California to Hawaii. Gray shaded region indicates interquartile

1265 range.

1266

1267

1268

1269 

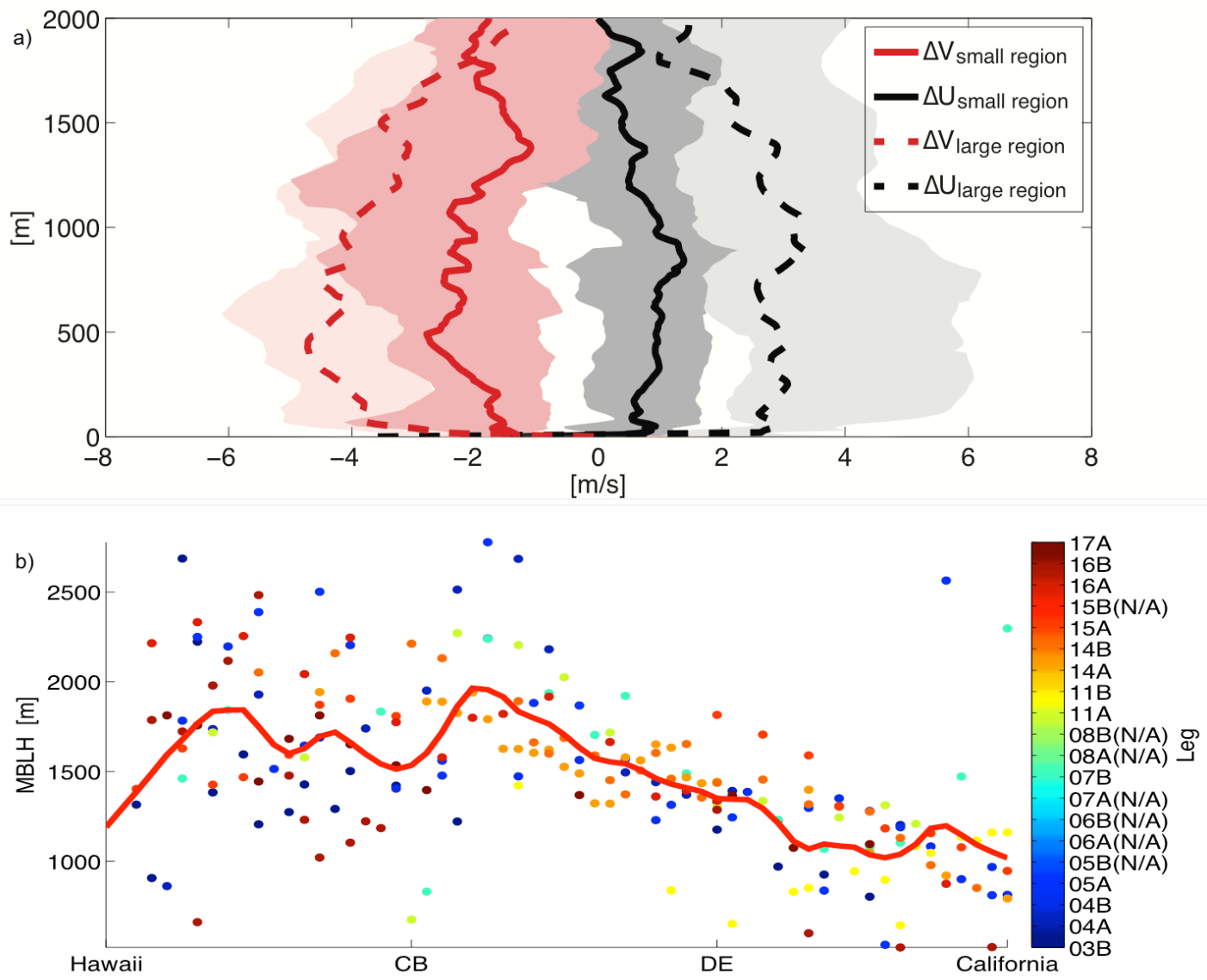

1271 Fig. 13. (a) Profiles of medians of $U$ wind difference of the composed $U$ wind east of CB

1272 and that west of $\mathrm{CB}$ in the small region (solid black line) and in the large region (dashed 1273 black line); same for $\mathrm{V}$ wind difference in the small region (solid red line) and in the

1274 large region (dashed red line). Shaded area indicates interquartile range, and (b) MBLH 1275 along normalized path from California to Hawaii. 


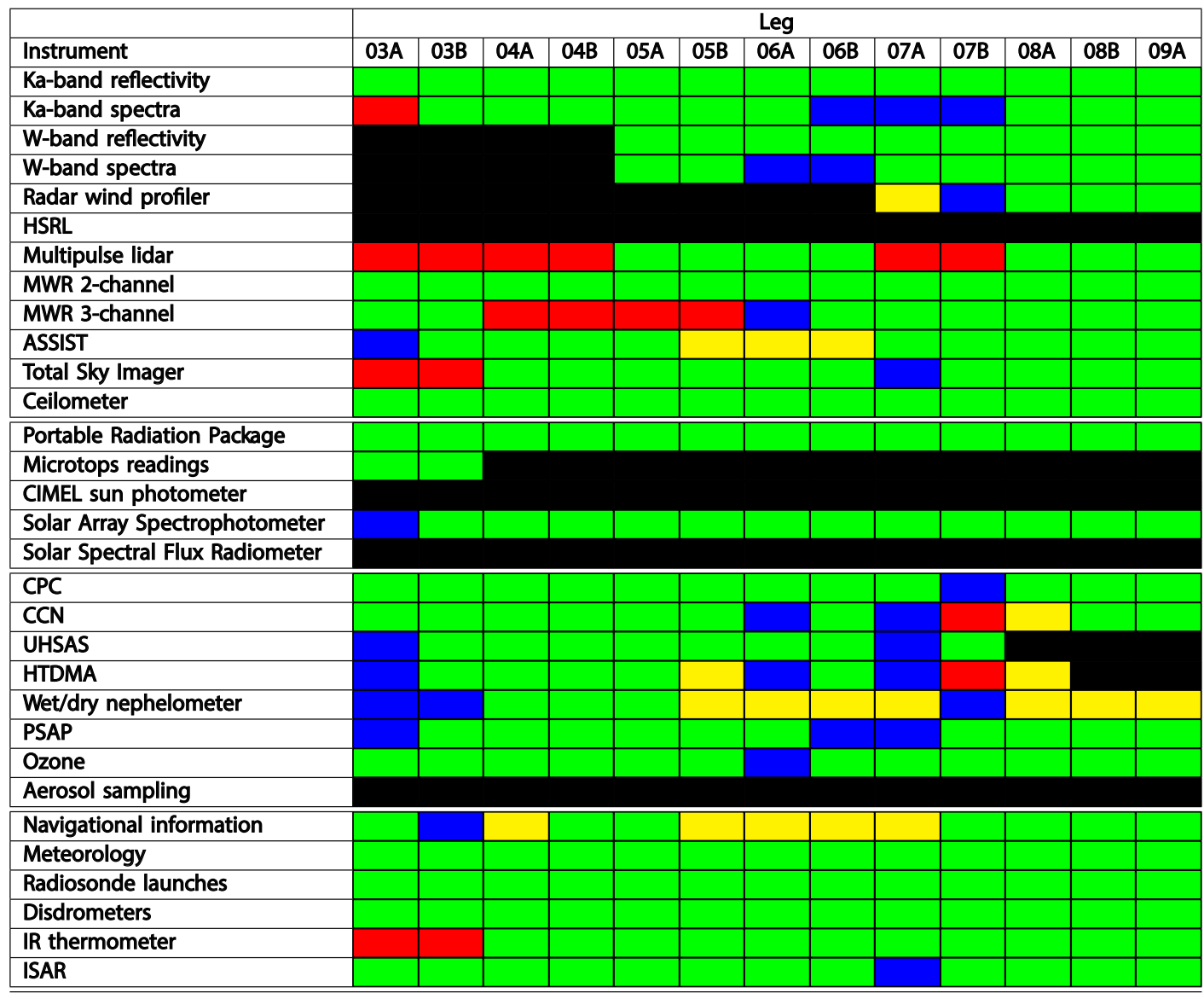

\begin{tabular}{|l|l|l|l|l|}
\hline No issue & Corrective maintenance or partial data & Questionable data & Instrument down & Not in service \\
\hline
\end{tabular}

1283 Fig. 14 MAGIC Instrument Status from Leg03A to Leg09B 


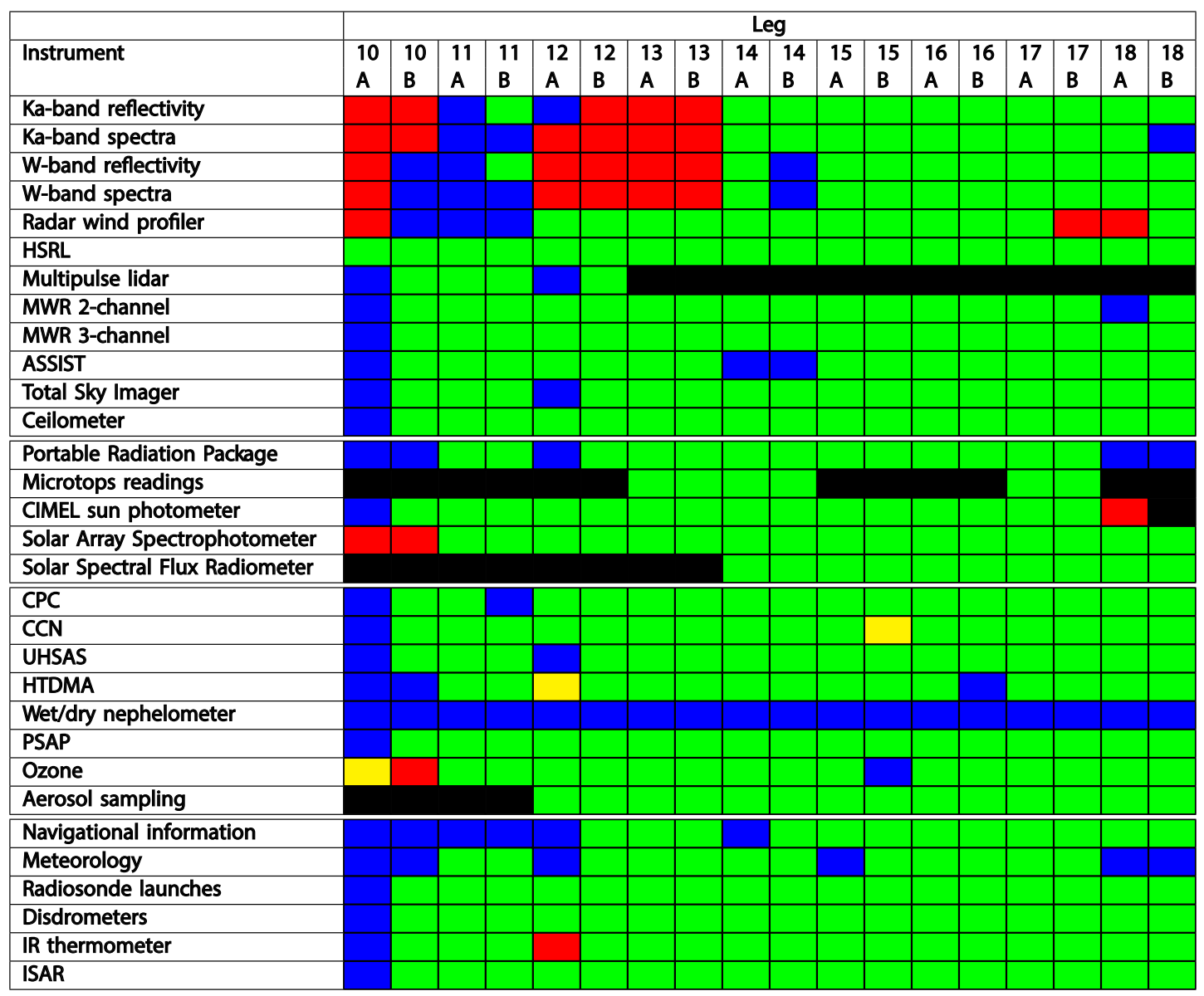

\begin{tabular}{|l|l|l|l|l|}
\hline No issue & Corrective maintenance or partial data & Questionable data & Instrument down & Not in service \\
\hline
\end{tabular}

1285 Fig. 15 MAGIC Instrument Status from Leg10A to Leg18B 
1292

1293

1294 